\section{TENSIONES Y \\ CONVERGENCIA: EL DISEÑO URBANO CONTEMPORÁNEO COMO ALTERNATIVA A LA CIUDAD DISPERSA Y DIFUSA'}

Constantino Mawromatis ${ }^{2}$

\section{Resumen}

Durante las últimas tres décadas se viene manifestando en la disciplina del diseño urbano un fenómeno en construcción que apunta hacia una concepción más integral y sostenible del crecimiento de las ciudades, con proyecciones de poder constituirse en alternativa real y viable respecto a la expansión urbana descontrolada. Este fenómeno se expresa a partir de la emergencia y progresiva convergencia de corrientes urbanísticas que se originan desde distintas aproximaciones y que tienden a coincidir sin embargo, en una actitud proactiva respecto al logro de mejores ciudades; corrientes que han derivado en nuevos referentes que se instalan como alternativas a la inanidad de los loteos residenciales. El presente artículo tiene por propósito identificar y

\section{TENSIONS AND CONVERGENCE: CONTEMPORARY URBAN DESIGN AS AN ALTERNATIVE TO URBAN SPRAWL'}

Constantino Mawromatis² 
contextualizar históricamente el fenómeno planteado, reconociendo la diversidad de las partes que lo componen, pero comprendiendo a la vez la lectura común que puede extraerse de cada planteamiento. La existencia de caminos aparentemente irreconciliables en las nuevas concepciones del diseño urbano, el de la recreación o adaptación del pasado y el de la anticipación del futuro, ha llevado la discusión teórica por sendas paralelas que, rara vez confluyen; no obstante, se evidencia crecientemente en la literatura especializada como también en algunos casos paradigmáticos, la concurrencia de principios que confirmaría el fenómeno como parte de un fortalecimiento de la disciplina en un marco de sostenibilidad.

\section{PALABRAS CLAVE: DISEÑO URBANO, CIUDAD DISPERSA, NUEVO URBANISMO, MOVILIDAD, ECOCIUDAD.}

Fecha de recepción: 21.11.12

Fecha de aceptación: 17.06.13

1 Artículo basado en la tesis doctoral en curso del autor, Escuela Técnica Superior de Arquitectura, Universidad Politécnica de Madrid. Director de tesis Dr. Julio Pozueta E.

2 Chile. Arquitecto, D.E.A., $\operatorname{Dr}(\mathrm{C})$ Escuela Técnica Superior de Arquitectura, Universidad Politécnica de Madrid. Profesor Asistente, Académico del Departamento de Urbanismo de la Facultad de Arquitectura y Urbanismo de la Universidad de Chile. Correo electrónico: cmawroma@uchile.cl of its components and understanding the similarities that can be drawn from each approach. The presence of seemingly irreconcilable conceptions of urban design, as the ones championed by the neo-traditional tendencies and the ones focused on innovation, has led to ongoing theoretic debate on parallel paths that rarely converge. However, specialized literature and some paradigmatic new towns increasingly reveal the concurrence of principles that may confirm this phenomenon as evidence of the strengthening of the discipline within a sustainability framework.

\section{KEYWORDS: URBAN DESIGN, URBAN SPRAWL, NEW URBANISM, MOBILITY, ECO-CITY.}




\section{Introducción}

El impacto que ha generado la "expansión urbana descontrolada"3 y la consiguiente ciudad dispersa y difusa ${ }^{4}$ sobre la habitabilidad de las ciudades contemporáneas ${ }^{5}$ ha ocupado buena parte de la crítica especializada de las últimas décadas y ha motivado el surgimiento de diversos planteamientos y propuestas urbanas en dirección a revertir o al menos mitigar los efectos de dicho crecimiento. Estas líneas de pensamiento crítico han derivado en determinadas corrientes alternativas al modelo predominante, particularmente en Europa y en los Estados Unidos, que a partir de los años ochenta y con particular fuerza desde mediados de los años noventa, han sabido articular sus idearios en función de una postura proactiva y pragmática, pero no por ello necesariamente menos propositivas o exploratorias. Estas corrientes propugnan la legitimación de modelos urbanísticos que ofrezcan mayores grados de sostenibilidad y habitabilidad. Esta visión de ciudad congrega a tendencias de distinta naturaleza y origen, que coinciden no

3 Se habla de expansión urbana descontrolada cuando la tasa de cambio del uso del suelo de rústico a urbano es superior a la tasa de crecimiento demográfico de una determinada zona durante un período determinado. (Agencia Europea de Medio Ambiente, 2006).

4 En los Estados Unidos de América, se conoce como el fenómeno del urban sprawl, o simplemente sprawl, término que reúne una serie de características del modelo y que simplifica su uso.

5 En referencia a los fenómenos que se suceden fundamentalmente a partir de la posguerra (Segunda Guerra Mundial). obstante, en la apreciación de ciertos valores implícitos en las ciudades tradicionales, unos de manera más literal, mientras que otros desde una reinterpretación innovadora.

Si bien el discurso generalizado hoy por hoy, pareciera concordar con la necesidad de mejorar las condiciones de habitabilidad abogando crecientemente por un desarrollo sostenible y por la necesidad de recuperar la vida de barrio, ello no se condice con la realidad predominante que se puede evidenciar en la formación de un periurbano difuso $^{6}$ o una interfase urbano-rural ${ }^{7}$ en diversos contextos geográficos y culturales. Esto se manifiesta principalmente en aquellos lugares que no poseen una larga tradición urbana, en donde prepondera el modelo suburbano disperso y monofuncional. Tal es el caso de la realidad norteamericana y en general de muchos países emergentes, en donde la especulación del suelo en la periferia urbana ocupa un importante sitial en la actividad económica local. Sin embargo, el fenómeno de la ciudad dispersa y difusa irrumpe igualmente en lugares con

6 Término utilizado por Carlos de Mattos (Mattos, 1999.)

7 Definido como los espacios geográficos donde se reproducen condiciones de insostenibilidad ambiental en estrecha relación con las dinámicas territoriales de lo urbano y lo rural. López, Delgado y Velasco, 2005.

revista invi º 79 / Noviembre 2013 / Volumen N²8: 125-163 127 
siglos de evolución histórica y con una marcada identidad urbana, como es el caso europeo, incluso en aquellos países de cultura mediterránea.

En efecto, es posible constatar que, a pesar de una conciencia pública tácita y generalizada respecto a la problemática urbana y, a las demandas reivindicativas respecto a los valores de una vida a escala humana, la expansión urbana descontrolada crece a un ritmo alarmante, agudizando el deterioro de las condiciones de habitabilidad. No obstante, ha surgido en el último tiempo el fenómeno anteriormente mencionado respecto a la emergencia de corrientes alternativas, tendencias que se exponen desde líneas de pensamiento y propuestas singulares, hasta movimientos de mayor organización, teniendo en común la convicción de las limitaciones y la insostenibilidad que presenta el modelo de crecimiento y de desarrollo actual. Aunque los modelos propiciados como alternativos no logran aún ocupar proporcionalmente un espacio significativo en el desarrollo urbano contemporáneo, sí han logrado instalarse como referentes que estimulan la reflexión y el debate, ya no tan sólo en el ámbito académico, sino que también crecientemente en las esferas de la opinión pública informada, influyendo en los ámbitos de toma de decisión, tanto en el sector público como privado. Prueba de ello es el apreciable incremento de proyectos que se materializan -especialmente en algunos países europeos-, a partir de esta visión alternativa, junto con creativas políticas urbanas que favorecen y estimulan el desarrollo sostenible.

\section{El sprawl en los Estados Unidos de América, sus efectos y transferencias}

La ciudad dispersa y difusa por definición comprende bajas densidades y se organiza desde la monofuncionalidad prescrita por el zoning 8 como instrumento de ordenación territorial. Es de carácter fragmentaria, posee escasa conectividad, es segregadora y excluyente por naturaleza. Las consecuencias son variadas y de diversa magnitud, dependiendo de los contextos y de la intensidad con el que el desarrollo se manifiesta. El modelo que opera desde las lógicas del mercado, se caracteriza también por el vínculo estructural que existe entre las inversiones inmobiliarias en megaproyectos de loteos residenciales con los llamados "nuevos artefactos urbanos" y la vialidad asociada a esta,

8 Referido al término norteamericano en relación a la subdivisión de un territorio en función de un uso en cada una de sus partes, regulando esencialmente las densidades y las actividades permitidas en cada zona.

9 Mattos, 1999 
lo cual da cuenta de un modelo urbanístico claramente orientado al automóvil, con configuraciones viales de geometría dendrítica ${ }^{10} \mathrm{o}$ arborescente ${ }^{11}$ en los conjuntos residenciales, limitando y dificultando de esta manera el encuentro de las personas ${ }^{12}$.

Este modelo norteamericano se ha convertido de hecho en la modalidad preponderante del crecimiento de las ciudades más dinámicas en cuanto al incremento económico y demográfico en el mundo ${ }^{13}$, dejando una huella apreciable sobre el medio natural y las formas de vida urbana en un tiempo relativamente corto. Cada vez se hace más evidente la escasez de áreas de expansión urbana mientras que la movilidad se hace menos sostenible por la escasa conectividad y por la baja densidad y dispersión de la periferia que además encarece o inviabiliza el financiamiento del transporte público, obligando a la dependencia del automóvil y saturando de esta manera la vialidad existente. Se genera consecuentemente una mayor demanda por nuevas infraestructuras viales, que a la vez sirven de incentivo para continuar con la expansión urbana en un círculo vicioso, comprometiendo en el intertanto las bases de una vida comunitaria y saludable.

Ello se puede constatar mayormente en los Estados Unidos de América, en donde este modelo se presenta en su versión más extrema y por mayor

10 Salingaros, 2007

11 Pozueta, 2009.

12 Gehl, 2006.

13 Worldwatch Institute, 2001. extensión en el tiempo. El llamado sprawl domina el paisaje de los asentamientos humanos norteamericanos y marca fuertemente la vida de sus habitantes. A modo de ejemplo, en una encuesta del Pew Center for Civic Journalism según versa en el sitio del Sierra Club ${ }^{14}$, la dispersión urbana junto a la delincuencia son dos de las preocupaciones principales de la mayoría de los estadounidenses a nivel local. La preocupación generalizada por la dispersión urbana se puede explicar por varios de los impactos concretos que introduce este modelo de expansión: la pérdida de áreas verdes a mano de la progresiva pavimentación asociada a las extensas superficies destinadas al tráfico rodado, la polución del aire, y el tiempo destinado a la circulación vehicular estimado en 55 días hábiles al año, según advierte la referida encuesta.

La expansión urbana descontrolada tiene ciertamente un costo social, como también uno económico. Las inversiones inmobiliarias se orientan de acuerdo a los incentivos ofrecidos, los cuales nacen de la voluntad y de la política urbana, tanto a nivel local como federal. El gran despliegue público a favor de un modelo urbanístico que incentiva la inversión privada en las periferias urbanas en los Estados Unidos, tiene un costo monetario para los contribuyentes que incrementa los niveles

14 Sierra Club, s.f. 
de insatisfacción de la población. Concretamente, y como lo indica el Sierra Club, se invierten considerables esfuerzos en la construcción de carreteras nuevas y más amplias, en la construcción de escuelas en los suburbios, en extender las infraestructuras sanitarias para el desarrollo en expansión, y en ampliar paralelamente los servicios de emergencia hacia la periferia urbana, subsidiando a los promotores inmobiliarios con diversos beneficios que provienen de programas locales, estatales y federales ${ }^{15}$.

Como evidencia de estas transformaciones de finales del siglo recién pasado, el U.S. Department of Housing and Urban Development ${ }^{16}$ señala que entre los años 1990 y 1998, la población suburbana creció en un $11.9 \%$, mientras que la población de los centros urbanos creció solamente un $4.7 \%$. A la fecha del informe, la población de los centros urbanos correspondía a un 38\% del total de la población metropolitana de los Estados Unidos, mientras que en los años setenta esta ascendía a un $45 \%$. Paralelamente, el territorio urbanizado se incrementa al doble de las tasas de crecimiento de la población. En los años noventa se vio efectivamente, un incremento en la expansión urbana en una proporción aproximada que duplica la tasa de los años cincuenta. Esta tendencia tiene su

15 Al respecto cabe agregar de acuerdo a Sierra Club que la mayor contribución federal a la expansión corresponde a la construcción de nuevas carreteras. En los últimos 50 años, se han construido en los Estados Unidos casi 4 millones de kilómetros de carreteras.

16 U.S. Department of Housing and Urban Development, 2000, p. 12. explicación en gran medida producto de los incentivos federales a proyectos inmobiliarios que se emplazan en las periferias urbanas, como también a una deficiente política de planificación a nivel estatal y federal, como se explica en los dos últimos informes del Sierra Club.

\section{La ciudad dispersa y difusa en el "improbable" contexto europeo}

En el marco de la globalización -que implica en la práctica las crecientes transferencias del modelo económico y cultural norteamericano a nivel global-, se han acelerado también los procesos de expansión urbana descontrolada en otros territorios y contextos. Latinoamérica junto a otras regiones emergentes están experimentando transformaciones en sus ciudades, incluso en aquellas de tamaño intermedio, lo cual se explica por el dinamismo de sus economías y por la creciente influencia de los ámbitos especulativos a partir de la liberalización de los mercados de suelo urbano y de la preponderancia del sector privado en la construcción de las ciudades. Paradójicamente, Europa no está ajena a 
dicho fenómeno, a pesar de su rica y larga tradición urbana, con ciudades más compactas y con cascos históricos densos y ricos en diversidad de usos y espacios urbanos. La dispersión según el informe Urban sprawl in Europe, the ignored challen$\mathrm{ge}^{17}$ "está especialmente presente como fenómeno, en las áreas urbanas del centro, sur y este de Europa, generando una creciente presión por recursos energéticos, infraestructura de transporte, y una demanda por cada vez más áreas de expansión urbana".

La dispersión en la periferia ya es propia de la modalidad del desarrollo urbano de muchas de las ciudades europeas. Aunque más reciente y de considerable menor magnitud en superficie que en el contexto norteamericano, el crecimiento por expansión descontrolada en Europa ${ }^{18}$, afecta a gran parte de la población, directa o indirectamente, reconfigurando el paisaje natural y cultural ${ }^{19}$. Ello tiene especial incidencia en un continente

17 European Environment Agency, 2006.

18 Como advierte el informe mencionado, “... la actual tendencia hacia la creación de nuevas áreas urbanas de baja densidad está generando un aumento del consumo. En los últimos 50 años, el espacio por persona en las ciudades europeas ha aumentado a más del doble. En los últimos 20 años, la superficie construida en muchos países de Europa occidental y oriental ha aumentado un $20 \%$, mientras que la población sólo ha crecido un 6\%".

19 Se refiere al caso de Europa occidental, donde, a diferencia del caso norteamericano "... ha habido cierta dinámica en la dirección opuesta. El parque automotriz y el tráfico rodado aumentan a tasas considerablemente más altas que en los Estados Unidos. Los estilos de vida suburbanos y de características semirurales son, cada vez más comunes". (Richardson y Bae, 2004). altamente poblado y con escasez relativa de territorios a urbanizar, como el europeo. Como se consigna en el mencionado Informe de la Agencia Europea de Medio Ambiente, "Europa es uno de los continentes más urbanizados de la Tierra. Alrededor del 75\% de su población vive en zonas urbanas". El informe continua señalando que "más de una cuarta parte del territorio de la Unión Europea se puede considerar suelo urbano"20. Se proyecta además, que en el año 2020, aproximadamente el 80\% de los europeos residirá en zonas urbanas, habiendo siete países en donde la proporción sería del 90\% o más.

La demanda de suelo crece y con ello se genera una presión para ampliar los límites urbanos, modificando y transformando el medio natural e impactando paralelamente el funcionamiento adecuado de las ciudades. Al ritmo actual la expansión urbana en Europa es en efecto insostenible. A modo de ilustración en el Informe citado de la Agencia

20 Agencia Europea de Medio Ambiente, 2006. 
Europea de Medio Ambiente ${ }^{21}$, se menciona que “... un reciente estudio de ámbito europeo revela que las ciudades crecen rápidamente y sin freno: más del 5 $\%$ en un decenio, equivalente a tres veces la superficie de Luxemburgo"22.

El diagnóstico es claro como lo demuestran las crecientes tasas de expansión territorial. En los últimos años esto se ha hecho cada vez más evidente y más actores se han visto en la necesidad de al menos abordar críticamente el crecimiento urbano disperso en función de proponer caminos alternativos que mitiguen las consecuencias o que incluso reviertan la tendencia vigente. Desde los años sesenta se viene advirtiendo de esta realidad, pero no es hasta las décadas de los ochenta y noventa en donde se aprecia el surgimiento de corrientes alternativas con un nivel de articulación y una visión pragmática que permite materializar nuevos modelos urbanísticos exitosos a una escala y proyección que pueda recoger las demandas por mayor calidad, sostenibilidad, diversidad y dinamismo en el desarrollo urbano actual.

21 Ibídem.

22 "En Europa, el crecimiento de las ciudades ha estado impulsado históricamente por el aumento de la población urbana, pero en la actualidad, a pesar de la escasa o nula presión demográfica, existen diversos factores que siguen impulsando la expansión", como los incentivos otorgados por los Fondos de Cohesión y por los Fondos Estructurales de la Unión Europea, "que financian el desarrollo de las infraestructuras como la mejora de conexiones de transporte y con ello propician la aceleración de la expansión descontrolada y el aumento de la movilidad personal." (Agencia Europea de Medio Ambiente, 2006).

\section{Orígenes y enfoques de las corrientes emergentes; un fenómeno en construcción}

Jane Jacobs y Lewis Mumford entre otros, ya advirtieron tempranamente de los impactos del modelo imperante que caracterizó el crecimiento urbano de la posguerra. Desde entonces múltiples han sido los planteamientos que buscan nuevas fórmulas y estrategias de desarrollo, y variados los intentos por clasificar las diversas líneas de pensamiento, tendencias, corrientes y movimientos, transitando por aproximaciones teóricas, como las derivadas de un pensamiento estructuralista a las del postestructuralismo; desde visiones exploratorias e innovadoras a planteamientos historicistas; como también desde la materialización de planes y proyectos que definieron una época, como los nouvelle cité o quartiers o las experiencias herederas de los new towns y la garden city. 
Realizando una lectura con limitada perspectiva histórica se puede reconocer, a partir de las últimas décadas, un nuevo fenómeno en construcción en el cual se distinguen esencialmente tres enfoques desde los cuales se puede caracterizar un fortalecimiento del diseño urbano, ya no tan sólo como emprendimientos aislados o acotados en el ámbito académico, sino que también como una aproximación real al desarrollo de las periferias urbanas desde una visión integral, pragmática y cimentada en principios que sustentan las respectivas propuestas que conforman un modelo alternativo ${ }^{23}$.

Estos tres enfoques identificados, desde donde se originan las distintas corrientes que reúnen los fundamentos esenciales de las miradas críticas al modelo disperso y difuso, se definen como: en primera instancia el enfoque neotradicional, una aproximación que surge como crítica al movimiento moderno y a la dispersión urbana, inspirándose en la "atemporalidad" de la arquitectura clásica y en la ciudad tradicional compacta, rescatando y adaptando la esencia y las condiciones que la caracterizan en función de ofrecer una mejora de la calidad ambiental desde las identidades regionales y locales; en segundo término, el enfoque de la movilidad, el cual postula que la calidad del diseño urbano radica esencialmente en una disposición conciente y sistémica de las tramas circulatorias

23 Hipótesis que se sustenta en la tesis doctoral del autor, en donde se definen los tres enfoques mencionados. de acuerdo a una optimización cualitativa de la movilidad urbana en función del hombre, congregando a los distintos actores del espacio viario de manera equitativa y eficaz; y el tercer enfoque, definido como el ecológico o medioambiental, cuya visión crítica del desarrollo cuantitativo propugna un equilibrio relativo entre el desarrollo económico, las necesidades sociales de las comunidades y el medio ambiente natural, planteando las condiciones para un diseño urbano integrador con un fuerte componente de participación ciudadana bajo una concepción holística.

Las corrientes alternativas que se desprenden de estos particulares enfoques han surgido en diversos momentos y con variadas características; emergen en un escenario de creciente empoderamiento ciudadano, en tiempos de una mayor conciencia ambiental y social y, con la convicción generalizada de las limitaciones de un desarrollismo que, en términos del territorio físico, se manifiesta en un crecimiento urbano por extensión, incremental y desarticulado, con las consecuentes repercusiones en la calidad de vida de la gente y en el deterioro del medio natural. Estas corrientes tienen distintos idearios y orígenes, algunos aparentemente irreconciliables y en permanente tensión; se articulan desde diversos énfasis y a partir de los enfoques indicados. En definitiva el ideario de estas corrientes 
se origina y se sostiene a partir de la convicción de posicionar a la disciplina del diseño urbano en su justa medida en la dinámica del desarrollo urbano contemporáneo; en el convencimiento de la relevancia del proyecto urbano en el ordenamiento del territorio y en el crecimiento de la ciudad contemporánea.

\section{El diseño urbano neotradicional}

El término neotradicional surge del inglés "neotraditional planning” (planificación neotradicional), consignado así en la publicación de Katz "The New Urbanism: toward an architecture of community"24, en donde él mismo atribuye este término a diversas publicaciones como The Atlantic, Travel \& Leisure, People and Smithsonian, las cuales hacían referencia a lo que se estaba evidenciando en los años ochenta en los Estados Unidos ${ }^{25}$.

Los principios de las corrientes que se sitúan en, o adscriben a esta línea de pensamiento, provienen de una aproximación en esencia arquitectónica y se asocian a una visión tradicionalista que define su actuar desde la continuidad evolutiva de la arquitectura y la ciudad, relevando la morfología y la

24 Katz, 1994, p. ix.

25 Katz es también un actor fundamental en la articulación del movimiento del Nuevo Urbanismo (New Urbanism), corriente neotradicional liderada por los escritos y trabajos de Duany y PlaterZyberk, y Calthorpe entre otros arquitectos norteamericanos. tipología en sus proyectos. Sus posturas surgen de la crítica a la aleatoriedad formal de la arquitectura contemporánea y del alejamiento del diseño como mecanismo para dar forma a los asentamientos humanos, apuntando a los loteos monofuncionales dependientes del automóvil y asociados a las lógicas territoriales del zoning norteamericano como parte fundamental en la degradación de las ciudades y la alienación de sus habitantes ${ }^{26}$.

Las corrientes neotradicionales se caracterizan también por adoptar y adaptar las identidades locales y regionales como parte fundamental en la elaboración de sus nuevas propuestas, apelando al anhelo de pertenencia y a la apropiación de los proyectos por parte de sus habitantes. Pero este reconocimiento de lo local que pudiere entenderse como una fortaleza, es también foco central de la crítica hacia esta tendencia, toda vez que las posturas neotradicionales que explotan el imaginario historicista en un eventual pastiche arquitectónico no reflejan la condición propia de la contemporaneidad. No obstante, las corrientes neotradicionales han sabido por otro lado, capturar y hacer suyos los principios que trascienden las adscripciones estilísticas, incorporando el oficio y el arte del diseño urbano en sus proyectos.

26 Krier en: Porphyrios, 1984; Krieger, 1991; Easterling, 1993. 
FIGURA 1. POUNDBURY.

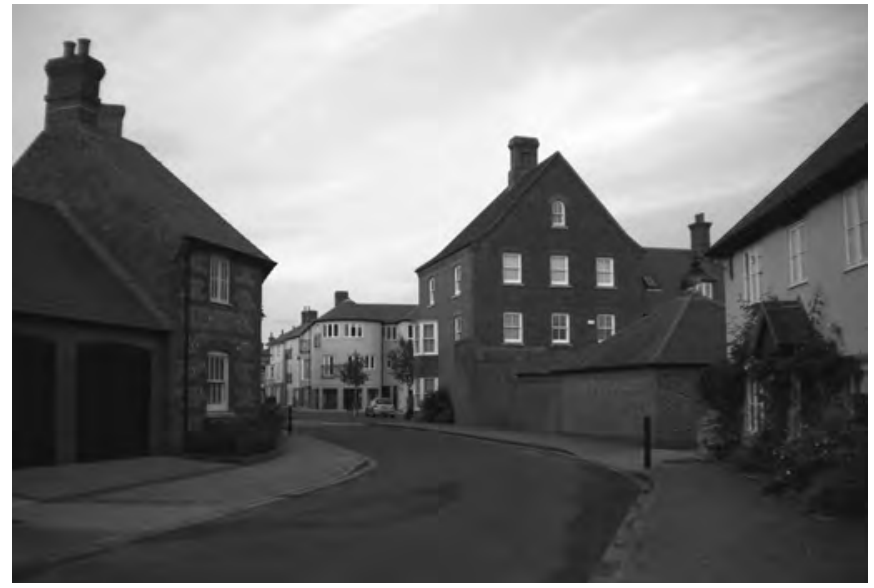

Fuente: autor

FIGURA 2. POUNDBURY EN EL CONTEXTO DE DORCHESTER Y SU CENTRO HISTÓRICO.

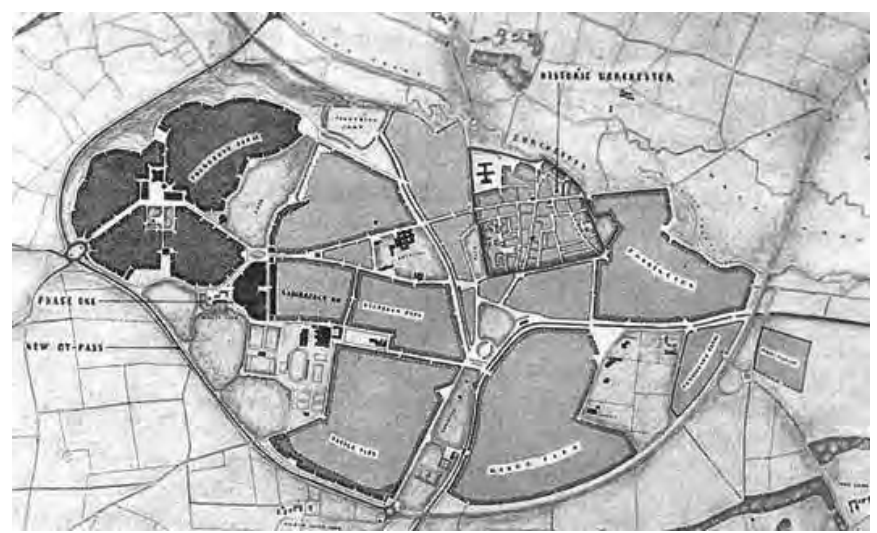

Fuente: Duchy of Cornwall 
Dentro de las corrientes neotradicionales Rob Krier y Leon $\mathrm{Krie}^{27}$ han sido fundamentales en la construcción de un discurso claro, simple y didáctico, poniendo en valor las virtudes de la ciudad preindustrial y de la arquitectura clásica, como lo caracteriza el propio Leon Krier, plasmando dichos planteamientos primero en propuestas teóricas, luego en concursos, para posteriormente materializar sus posturas en algunos recientes proyectos que gozan de resonancia internacional, trascendiendo inicialmente y con mayor fuerza en el contexto norteamericano que en el suyo propio, el europeo. Entre las experiencias aún en construcción destaca particularmente el caso de Poundbury de Leon Krier, una neo-aldea urbana $^{28}$ concebida a finales de la década de los ochenta, y prevista por las autoridades locales como una extensión urbana de la ciudad de Dorchester. Patrocinada por el Príncipe de Gales ${ }^{29}$ en terrenos del Ducado de Cornwell, se ha consolidado como un referente paradigmático del urbanismo neotradicional, a la vez que ha sido foco de la crítica tanto por su apego a la arquitectura historicista como por su carácter

27 Cabe señalar que a pesar de compartir un discurso común en la esencia, los hermanos Krier - Leon y Robert (Rob)- han transitado por carriles independientes tanto en su producción literaria, como en sus respectivos ejercicios profesionales.

28 Término utilizado por el autor para referirse a los urban villages de Europa, sugiriendo el contexto rural en donde suelen enplazarse estos proyectos.

29 El Príncipe Carlos ha sido un activo promotor de los valores tradicionales de las ciudades, destacando su libro "A Vision of Britain". elitista respecto a su vecina Dorchester ${ }^{30}$. El propio Alex Krieger, conocedor y editor de escritos sobre el Nuevo Urbanismo y las corrientes neotradicionales en general, se refiere a Poundbury como un buen ejemplo que da cuenta de los atributos de las configuraciones o tramas urbanas tradicionales que definen claramente el espacio público a partir de la fachada urbana, sin embargo lamenta al mismo tiempo que se haya optado por un "pastiche historicista" en su arquitectura ${ }^{31}$. Ciertamente la arquitectura que propugna Krier invita al cuestionamiento de las posturas neotradicionales que parecieran nutrirse de la nostalgia por el pasado, negando toda relación con la exploración creativa que supone la contemporaneidad. Pero por otro lado, cabe no obstante destacar la especial atención prestada al buen diseño en sus proyectos, que se conciben desde la voluntad de enriquecer la vida cotidiana de sus habitantes, trascendiendo las adscripciones estilísticas y los eventuales resoplos innovadores. Las pequeñas manzanas o insulas -como suele describirlas Krier- multiplican el número de calles y con ello refuerza la importancia

30 Se puede matizar respecto a su condición elitista, tomando en cuenta la diversidad de tipologías residenciales, unidades orientadas tanto a la propiedad como al alquiler. Según el propio Ducado de Cornwell, se proveen unidades de interés social repartidas a lo largo del proyecto, velando por la diversidad e integración de su población.

31 Moor y Rowland, 2006, p.22. 
del espacio público en el proyecto, en un compromiso ideológico del arquitecto respecto al diseño urbano como una manifestación hacia lo público. La configuración de plazas, de plazoletas y del espacio viario de Poundbury junto a la diversidad de su arquitectura, se proyectan en consideración a la presencia del peatón, remarcando vistas y ofreciendo proporciones equilibradas entre el vacío y lo construido, no obstante reconocer la preponderancia del automóvil en un entorno suburbano. El tejido urbano se compone a partir de ejes estructurantes y barrios de configuración orgánica que emulan la granulometría del centro histórico de Dorchester, y a la vez se constituye como continuidad de la trama existente, desvirtuando con ello la recurrente crítica en relación a la falta de conectividad que presentarían los proyectos de orden neotradicional respecto a los asentamientos contiguos.

Otros referentes notorios de las corrientes neotradicionales en Europa lo constituyen las obras de Rob Krier y su socio Christoph Kohl, entre las que destacan los casos recientes de Brandevoort y Citadel Broekpolder en los Países Bajos, y el nuevo distrito de Kirchsteigfeld ${ }^{32}$ en Potsdam, Alemania. Estos referentes se muestran como un contrapunto al desarrollo difuso de los suburbios convencionales presentando configuraciones compactas, con centros claramente definidos y bordes expresamente delineados. El

32 James-Chakraborty, 2001. caso holandés es particularmente rupturista respecto a lo que prevalece en ámbitos del desarrollo suburbano, ofreciendo un modelo de densidades mayores $^{33}$ con edificaciones de altura media y fachada continua, concebido a partir de los principios que caracterizan a los poblados regionales, con un centro, el "Veste", y barrios constituidos por pequeñas manzanas en torno a áreas verdes. Se hace alusión a la ciudad histórica amurallada, emplazando edificaciones de fachada continua en su borde junto a una canalización en su perímetro exterior. Esta "cita" historicista claramente no guarda relación con la realidad contemporánea, sin embargo resulta efectiva como recurso morfológico que acentúa la condición de ciudad compacta y restituye la separación campo-ciudad en el contexto del periurbano difuso. Como resultado se logra generar un tejido físico con mejores condiciones para animar el espacio público, lo cual apoyado por la mixtura de usos, permite caracterizar a estos proyectos como experiencias urbanas dentro de un contexto eminentemente suburbano. Pero no es solamente la condición compacta y la mezcla de funciones que hace atractiva a estas experiencias, sino -como lo explica el propio Rob Krier-, es "el tejido urbano [concebido] de acuerdo a una escala humana, preocupado de la calidad arquitectónica de las viviendas, la red de calles y plazas, la localización de edificios públicos... naturalmente sin excluir la correcta consideración de todos

33 La Veste en Brandevoort alcanza la densidad bruta de 75 viviendas por hectárea.

revista invi № 79 / Noviembre 2013 / Volumen № 28: 125-163 137 
los aspectos funcionales ${ }^{\prime 34}$, lo que permite el logro de mejores ciudades.

Paralelamente se distinguen en el continente europeo otros casos singulares menos difundidos, que surgen a partir de los principios del urbanismo neotradicional y que apelan en lo formal a la interpretación histórica recurriendo a la construcción de identidad en base a una inspiración regional, como es el caso de Heulebrug ${ }^{35}$ en los márgenes de la ciudad costera de Knokke-Heist, Bélgica. Esta propuesta captura la tradición belga de un desarrollo suburbano basado en la vivienda unifamiliar ${ }^{36}$ y por tanto se puede situar más cercana a los proyectos del Nuevo Urbanismo norteamericano que sus símiles europeos. Por otro lado, la nouvelle cité o quartier Le Plessis-Robinson perteneciente al municipio del mismo nombre en las afueras de la capital francesa, se inspira en la tradición urbana parisina con sus edificios decimonónicos. Este último caso forma parte de una política urbana del municipio francés para revertir el deterioro urbano, optando a finales de los años ochenta y principios de los noventa por favorecer la inserción de proyectos que marcaran una alternativa respecto a la futilidad del paisaje suburbano y de los bloques de vivienda colectiva modernistas. Se eligió

34 Ver entrevista a Rob Krier en Sevilla Buitrago, 2012, p. 122. 35 Proyectado por los arquitectos Duany \& Plater-Zyberk.

36 Kostof, 1992, p. 65. por tanto, el camino por un desarrollo distinto a la dispersión territorial con el propósito de iniciar un proceso de transformación de un contexto suburbano a uno de carácter más urbano, con mayor diversidad de usos y una morfología más compacta, ofreciendo un ambiente que favorece el uso de los espacios públicos y el encuentro espontáneo de sus habitantes a través de la caminata por sobre el uso del automóvil para las actividades cotidianas. Entre sus diversas etapas destaca el Coeur de Ville o nuevo centro del distrito ${ }^{37}$, que acoge la mezcla de funciones con el comercio, los restaurantes y los cafés en las plantas bajas y con la vivienda en los pisos superiores, recurriendo al templado de tráfico para compatibilizar los requerimientos de conectividad viaria con las condicionantes de la escala humana. La altura de las edificaciones es de un promedio de cinco pisos con una arquitectura de reminiscencia palaciega que reinterpreta el neoclásico francés de París, recurso que identifica a este proyecto como un claro referente de las líneas neotradicionales. Este caso acoge densidades particularmente altas para los contextos suburbanos, contando en sus 12 hectáreas con una densidad poblacional mayor que otros proyectos de vivienda en altura $^{38}$, proporcionando a la vez

37 Proyectado por François Spoerry.

38 Según Siegel la densidad bruta del barrio de Coeur de Ville es de 67 habitantes / acre, superior a por ejemplo la densidad bruta de proyectos de vivienda en altura tipo torres, emplazados en parques, tales como Paris Rive Gauche que no supera las 46 personas por acre (Siegel, 2012). 
FIGURA 3. BRANDEVOORT.

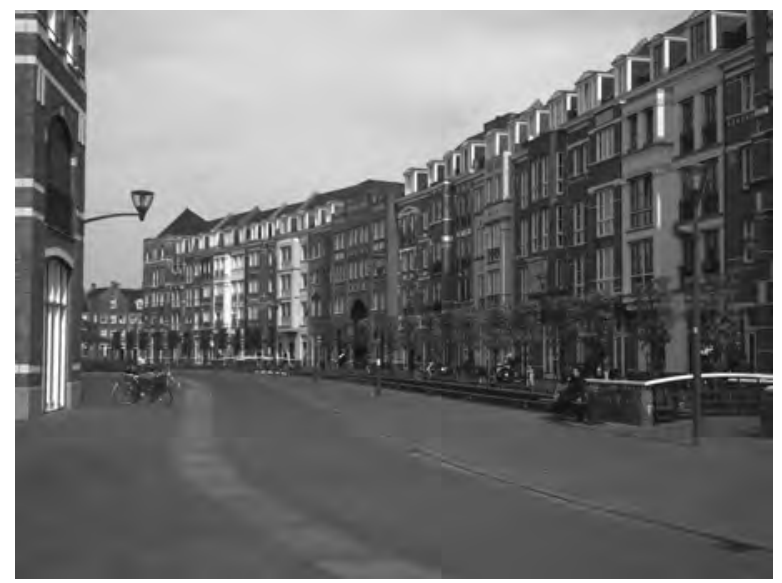

Fuente: autor.

FIGURA 4. HEULEBRUG.

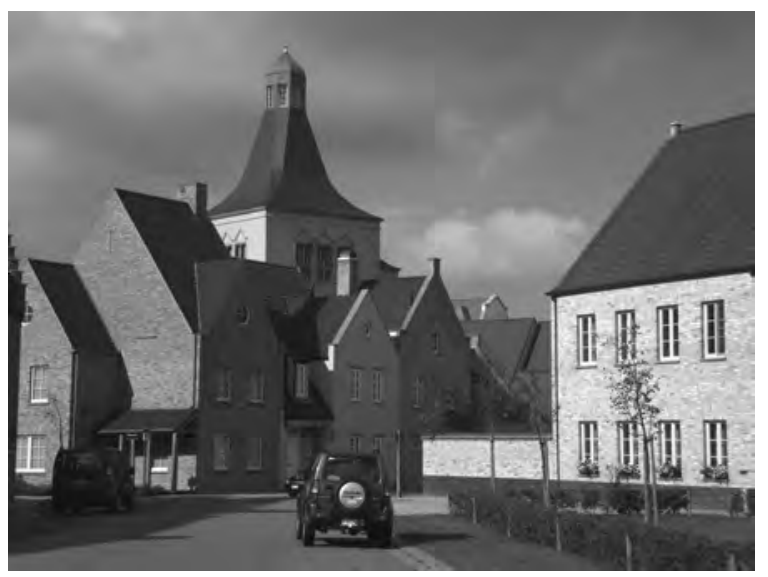

Fuente: autor 
un entorno de gran atractivo y calidad ambiental a unos 2000 residentes y proveyendo paralelamente, un $10 \%$ de vivienda social.

Tanto Heulebrug con una configuración esencialmente suburbana, como los nuevos proyectos de Le Plessis Robinson con un carácter más urbano, se entienden como extensiones en el contexto de la periferia de ciudades consolidadas, y como tales, presentan un avance substancial en cuanto a incorporar muchos de los atributos de la vida urbana a localidades alejadas que dependen fundamentalmente del automóvil y que usualmente descuidan el espacio público como lugar natural del encuentro ciudadano.

Estos referentes paradigmáticos de las corrientes neotradicionales en el diseño urbano recogen -más allá del imaginario historicista y la crítica que suscitan-, la esencia de los planteamientos de los movimientos de mayor organización, en cuanto a proveer las condiciones adecuadas para que la gente pueda realizar sus actividades cotidianas en el marco de un depurado diseño de los espacios públicos. Sus propuestas se

140 revista invi № 79 / Noviembre 2013 / Volumen № 28: 125-163 sustentan en la diversidad de usos, en la concepción de una movilidad interna que facilita e incentiva el desplazamiento a pie y en bicicleta, en los estímulos que provee el diseño del espacio público en cuanto a sus proporciones, vistas, fachadas, texturas, mobiliario y patrones compositivos, acogiendo diversas manifestaciones comunitarias y culturales, y con ello contribuyendo positivamente a la calidad ambiental del espacio urbano y a la convivencia entre sus habitantes. Es en este sentido que las propuestas neotradicionales se declaran crecientemente como referentes de una notoria tendencia hacia la sostenibilidad, derivando desde posturas inclinadas originalmente a una concepción morfológica del diseño urbano -como puede evidenciarse en los primeros dibujos de Leon Krier-, hacia aproximaciones propias de idearios medioambientales, formulando discursos que tienden a converger respecto a otras líneas de pensamiento más cercanas a la innovación en las propuestas urbanas.

En los Estados Unidos por su parte, el Nuevo Urbanismo ${ }^{39}$ constituye un movimiento de gran influencia

39 Se refiere a la corriente del Nuevo Urbanismo, New Urbanism en inglés; acuñado por Peter Katz como ya se ha mencionado anteriormente. Algunos autores se refieren también al Neo Urbanismo. Es un movimiento inspirado en los Garden City, las unidades vecinales de Clarence Perry y el City Beautiful Movement de finales del siglo XIX y comienzos del siglo XX; surge al alero de los planteamientos de Leon Krier y se sustenta paralelamente en los principios urbanísticos esgrimidos por autores clásicos como Jane Jacobs, Christopher Alexander y Raymond Unwin, entre otros, conformando la base de la concepción del llamado enfoque neotradicional. 
FIGURA 5. COEUR DE VILLE, LE PLESSIS-ROBINSON.

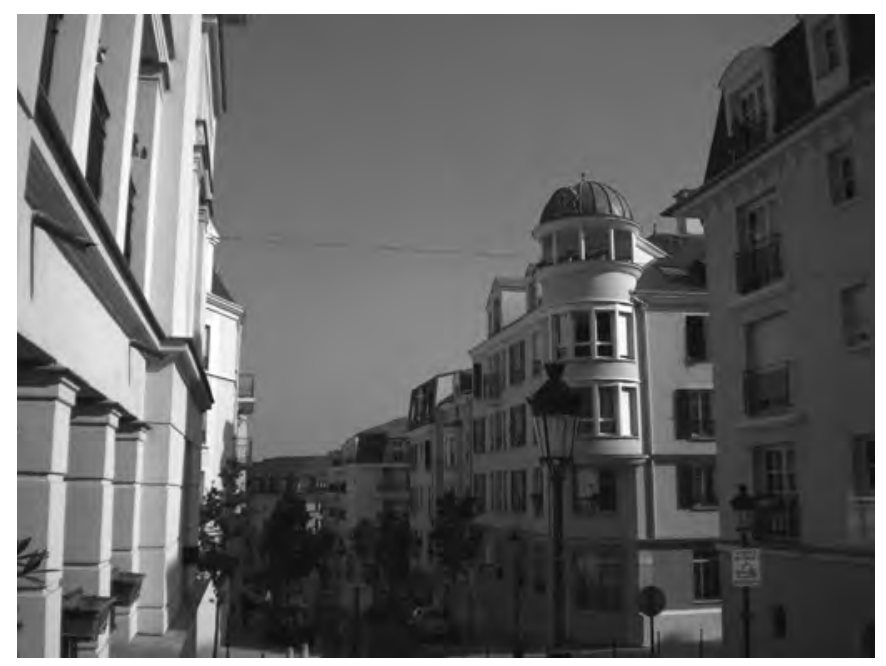

Fuente: autor

FIGURA 6. SEASIDE.

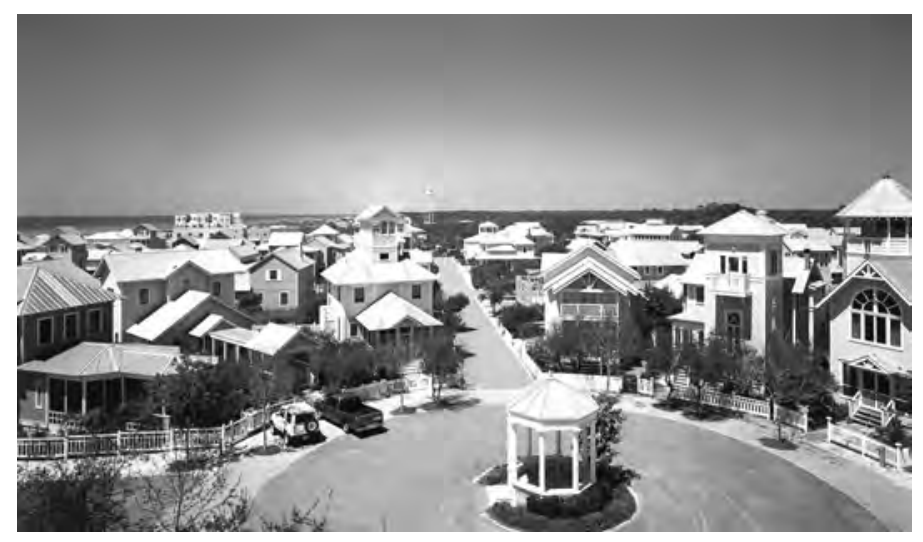

Fuente: eslarp.uiuc.edu 
que ha trascendido internacionalmente. Este movimiento es esencial en la comprensión del diseño urbano neotradicional. Surge a partir de las contribuciones de los arquitectos Andres Duany y Elizabeth Plater-Zyberk, destacándose paralelamente la figura de Peter Calthorpe con un particular enfoque hacia la movilidad. Peter Katz por su lado, fue quien articuló y coordinó las labores del movimiento del Nuevo Urbanismo en relación a su formación y a los Congresos CNU (Congress for the New Urbanism) ${ }^{40}$, a través de sus miembros fundadores Elizabeth Moule, Stefanos Polyzoides, Dan Solomon, los propios Duany y PlaterZyberk, y Peter Calthorpe.

En el caso de Duany y Plater-Zyberk ${ }^{41}$-pioneros y principales referentes del movimiento-, cabe relevar que corresponde a esta oficina de arquitectos proyectistas, algunas de las experiencias neotradicionales precursoras, entre las que destaca Seaside, primera experiencia atribuible a la llamada planificación neotradicional en los Estados Unidos. Es un proyecto costero en el noroeste del estado de la Florida que fue impulsado por el promotor inmobiliario Robert Davis a comienzos de los años ochenta. A diferencia de los loteos residenciales acogidos al zoning, Seaside se concibe a partir de un instrumento basado en la forma urbana, capturando a la vez las tradiciones sureñas de la arquitectura norteamericana y evocando a la unidad vecinal de Clarence Perry. Incorpora usos mixtos compatibles con la residencia y ofrece condiciones para una mayor diversidad en la vivienda y en la movilidad. Los predios son menores a lo típicamente ofrecido en el contexto suburbano norteamericano, con viviendas unifamiliares mayoritariamente de dos y hasta tres pisos, logrando con ello una configuración más compacta y una mayor densidad en relación a otros proyectos en similares contextos, provocando un menor impacto relativo sobre el territorio y las infraestructuras asociadas a la expansión urbana.

Posteriormente, el estudio de Duany y Plater-Zyberk se ha consolidado a finales de la década de los ochenta con proyectos como Kentlands en el estado de Maryland, y Windsor y Wellington, ambos en el estado de la Florida. Hoy por hoy cuentan con más de 300 proyectos sobre el espacio habitable en los Estados Unidos e internacionalmente, destacando por su pragmatismo y capacidad de gestión. Han contribuido paralelamente al diseño de normativas que promueven el modelo neotradicional, tal como el T.N.D. (Traditional Neighborhood Design and Development); son además autores de los transect-based codes y el SmartCode, promoviendo la instalación de instrumentos alternativos al zoning.

40 Congress for the New Urbanism, 1999.

41 Andres Duany y Elizabeth Plater-Zyberk, socios principales de Duany Plater-Zyberk \& Company, mantienen sus oficinas principales en Miami, Estados Unidos. 
Para entender los planteamientos de Duany y Plater-Zyberk como el de sus seguidores, es necesario situar las propuestas que desarrollan, en el contexto cultural norteamericano y por tanto, asumir la realidad eminentemente suburbana de los Estados Unidos, el imaginario del llamado sueño americano y la fuerte presencia de la industria automotriz durante el siglo XX. En dicho contexto es pertinente recordar las palabras que repite Duany frente a la crítica de sus detractores que reclaman un mayor compromiso urbano, señalando que primero se debe procurar "civilizar a los suburbios" antes de pretender desafíos mayores. Es por cierto, un avance importante el poder incorporar un desarrollo alternativo viable al sprawl que domina el paisaje norteamericano, rescatando la tradición del diseño urbano por sobre los megaproyectos monofuncionales acogidos al zoning.

Estos proyectos, junto a los aportes de diversas oficinas de arquitectura afines, como Dover $\& \mathrm{Kohl}^{42}$, Elizabeth Moule \& Stefanos Polyzoides, Daniel Solomon \& Kathryn Clarke y, por sobre todo con la visión integral de Peter Calthorpe, contribuyen a entender lo que en los años ochenta se estaba generando como un fenómeno en construcción, una tendencia hacia el reconocimiento de los valores del buen diseño y de la concepción urbana en los

42 Hoy Dover \& Kohl Company, de los socios fundadores Victor Dover y Joseph Kohl. ámbitos del suburbio, contribuyendo a la vez a una mejor experiencia de vida para sus habitantes. Esta tendencia, aprovechando la visibilidad en los medios, se fue constituyendo como una corriente de gran impacto en la opinión pública, articulando su discurso teórico con el negocio inmobiliario, transitando paralelamente entre el ejercicio profesional $y$ las aulas universitarias ${ }^{43}$.

Existe un amplio espectro de casos asimilables a este enfoque, en donde se pueden reconocer distintos grados de coherencia entre el planteamiento teórico y la materialización de dichos discursos en proyectos reales, distinguiéndose ciertas experiencias que buscan recrear la esencia de ambientes probados y reconocidos que ofrezcan efectivamente mayores niveles de habitabilidad en beneficio de la calidad de vida de sus habitantes, por sobre otras que parecieran orientarse más bien a la búsqueda de imágenes seductoras relacionadas por un lado, a estrategias de mercadeo y por otro, circunscritas a un imaginario romántico que podría singularizarse como cercanas a un urbanismo culturalista, de acuerdo a las teorías consignadas por François Choay en los años sesenta. En este ámbito cabría situar a algunos proyectos como el caso de Jakriborg, en Suecia, o las experiencias iniciales de François Spoerry en Port-Grimaud, que se centran

43 Elizabeth Plater-Zyberk es Decana de la Escuela de Arquitectura de la Universidad de Miami (School of Architecture, University of Miami).

revista invi № 79 / Noviembre 2013 / Volumen $N^{\circ} 28:$ 125-163 
FIGURA 7. KENTLANDS.

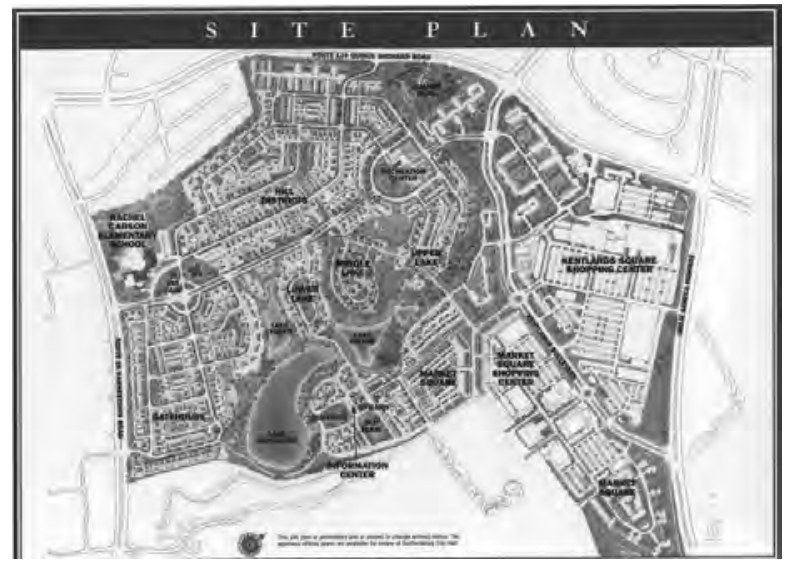

Fuente: kentlakes.com

\section{FIGURA 8. LA NEO-ALDEA URBANA DE JAKRIBORG.}

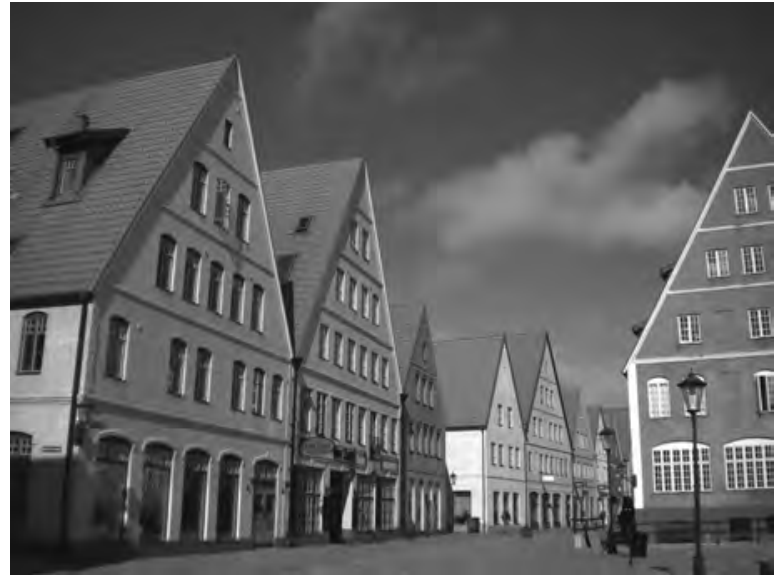

Fuente: autor. 
fundamentalmente en los aspectos de la imagen urbana por sobre los principios que sustentan las corrientes de mayor profundidad conceptual.

\section{La movilidad como principio orientador en el diseño urbano}

La movilidad ha dictado históricamente el tamaño y muchas de las características de los asentamientos humanos. Hoy, las aproximaciones desde la movilidad en el diseño urbano contemporáneo surgen esencialmente de la necesidad de revertir los impactos de la preeminencia del automóvil, ya sea esto último producto de las transformaciones sobre el territorio asociadas a la suburbanización progresiva o bien fruto del dogmatismo del urbanismo modernista. Este enfoque resulta fundamental en la concepción de diversos planteamientos alternativos que se centran en la importancia de la movilidad sostenible y en la equidad en el uso del espacio viario de una ciudad, en una concepción integral en donde el peatón recupere su lugar frente al tráfico rodado. Esta es una preocupación que ha estado presente por muchas décadas, ya sea desde una visión reivindicatoria del peatón, hasta la búsqueda de innovadoras formas de desplazarse en la ciudad, procurando mayores grados de conectividad y animación del espacio público.
Para señalar la importancia de una visión integral de la movilidad en beneficio del habitante y de la sostenibilidad en la ciudad contemporánea, se puede recurrir a referentes lejanos en el tiempo como el "Finger Plan" del área metropolitana de Copenhague - desarrollado en los años cuarenta y promulgado en 1947-, que establece las directrices para la expansión de la ciudad a través de una estructura radial de corredores urbanos en donde se desarrollan los suburbios de acuerdo a un plan de transporte público que haga efectiva la conectividad con el casco histórico de la ciudad, dejando las áreas intersticiales sin urbanizar de tal modo de asegurar la cercanía de todos sus habitantes a las áreas verdes y naturales. Por otro lado, en un ejemplo más cercano, se puede apelar a la experiencia de la Red Integrada de Transporte de Curitiba, que ha posicionado a la ciudad brasileña como "capital verde" y uno de los mejores ejemplos de urbanismo ecológico según un documento del Plan de Acción sobre Ecoinnovación de la Comisión Europea del Medio Ambiente ${ }^{44}$. Pero es en las últimas décadas y a raíz de la insostenibilidad de los modelos urbanos vigentes en relación al aumento explosivo del parque automotriz y a la expansión urbana descontrolada, que la movilidad sostenible emerge como concepto, cobra urgencia y concita crecientemente una atención transversal, estableciéndose como prioridad, al menos en los ámbitos académicos y disciplinares.

44 Comisión Europea del Medio Ambiente, 2011. 
La movilidad sostenible busca en efecto, organizar el uso de los medios de transporte y de la movilidad urbana en general, de manera de minimizar las consecuencias negativas sobre el espacio público y sobre el medio ambiente. Para ello se considera esencial el disminuir la dependencia del automóvil y el fomentar paralelamente el uso del transporte público, la bicicleta y la caminata de manera integrada y racional. Ya en 1963 se forma la International Federation of Pedestrians (IFP), una agrupación internacional de peatones con sede en Suiza, de la cual se desprenden, a partir del año 2000, el movimiento y las conferencias de Walk$21^{45}$, que tienen por finalidad defender el desarrollo de comunidades saludables, sostenibles y eficientes, donde la gente pueda elegir el caminar por sobre otros medios. Similarmente en la ciudad europea, se recuerdan los tempranos esfuerzos por proveer al peatón de espacios de calidad destacando el caso del arquitecto danés Jan Gehl, precursor en la peatonalización de áreas urbanas en la posguerra, y reconocido por su intervención de Stróget en Copenhague, en 1962. Gehl es referente fundamental para comprender y plantearse frente al diseño urbano desde la perspectiva y las necesidades del ciudadano a pie, abordando cualitativamente el espacio urbano. Su aporte no considera sesgos en cuanto a compromisos de dogma o estilo arquitectónico situándose como una Figura transversal a diversas aproximaciones a la problemática urbana.

45 Walk-21 es fundada por John Butcher en 1999.
Cabe destacar paralelamente, planteamientos como los de J. H. Crawford en su libro Carfree Cities, donde advierte de la necesidad de recuperar el espacio urbano para las actividades humanas ${ }^{46}$. Crawford propone implementar soluciones de diseño que, teniendo en cuenta la calidad de vida de los individuos y de las comunidades, optimicen la habitabilidad tanto de las ciudades existentes como de los nuevos desarrollos urbanos. Sus principios se basan fundamentalmente en las condiciones que facilitan el actuar del peatón por sobre cualquier otro medio de transporte, incluso el público, lo cual es posible exclusivamente bajo un modelo de ciudad compacta.

Ciertamente, se puede apreciar en el presente una mayor disposición a replantear la movilidad en las ciudades contemporáneas principalmente en los países del norte del continente europeo, y recobrar con ello los espacios urbanos para el peatón con nuevos diseños viarios y con las recomendaciones para considerar a los peatones en el planeamiento, el diseño urbano y la arquitectura ${ }^{47}$. El caso de Vauban en Friburgo, entre otros distritos de similar concepción en Alemania, es una prueba de la voluntad y del compromiso ciudadano con los modelos urbanísticos que se centran en las necesidades cotidianas de sus habitantes, en donde la movilidad constituye una variable fundamental en 
FIGURA 9. STRǿGET, COPENHAGUE.

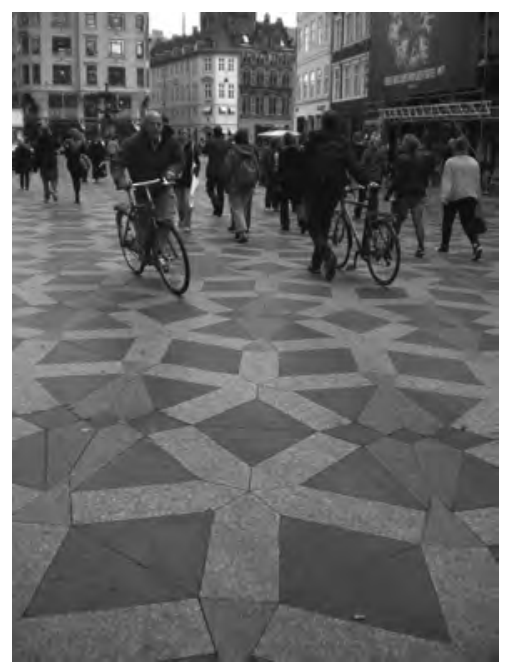

Fuente: autor

FIGURA 10. VAUBAN.

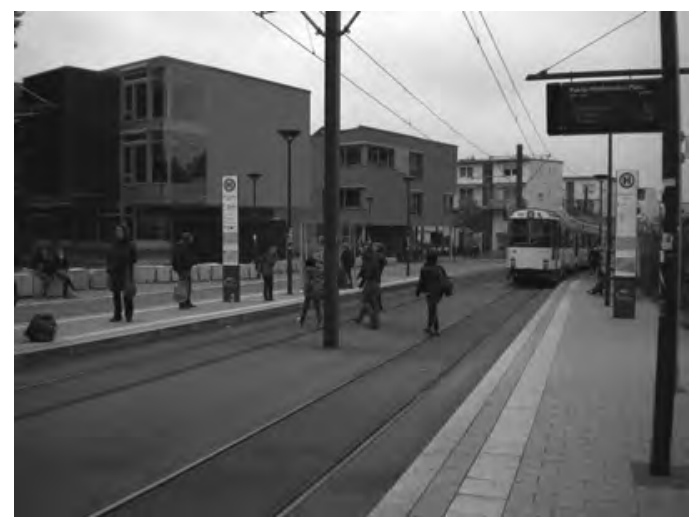

Fuente: autor 
la configuración de las ciudades. Se caracteriza por su cooperativismo en la gestión, por su administración del distrito y por sobre todo por el acuerdo ciudadano de favorecer el transporte público por sobre el automóvil; se constituye además, como uno de los ejemplos paradigmáticos de los carfree districts, que minimiza el uso y acceso del automóvil, privilegia el uso de la bicicleta y el libre desplazamiento de peatones, y potencia correspondientemente las redes de transporte público, especialmente el tranvía. La estructura del proyecto colabora en tal sentido, ya que la disposición de la trama urbana se orienta de tal forma que cada manzana se abre al eje central que reúne el comercio y los servicios varios, y en donde se emplaza paralelamente el tranvía que comunica al distrito con el centro de la ciudad. En tal sentido Vauban emblema del urbanismo ecológico-, puede considerarse un ejemplo que favorece la conectividad a partir del transporte público; no obstante surgen críticas respecto a su emplazamiento suburbano y a las políticas de un crecimiento por extensión, contraviniendo paradójicamente la vocación ecológica que caracteriza a la comunidad de Friburgo.

Desde una dimensión de mayor especificidad habría que destacar las medidas de templado de tráfico y los nuevos conceptos que denotan la creciente atención por la equidad en la movilidad y la movilidad sostenible, como los woonerf en los Países Bajos o Verkehrsberuhigter Bereich en Alemania, genéricamente denominados como shared space o espacio compartido ${ }^{48}$; se refieren esencialmente a la eliminación de las barreras existentes entre los distintos actores en el espacio viario -peatones, bicicletas, automóviles, etc., en determinados contextos y circunstancias para incentivar el uso responsable del espacio urbano, limitando la velocidad del automóvil e invitando al desplazamiento compartido. Esta concepción de movilidad es hoy asumida como un aspecto esencial del diseño urbano contemporáneo en cualquier proyecto que se consigne como alternativo al modelo predominante. De hecho es parte constitutiva de muchos de los proyectos de orden neotradicional, que han hecho propia esta concepción más equilibrada de la movilidad, como de igual forma figura en propuestas innovadoras y provocativas en cuanto a su creatividad.

También en Norteamérica se pueden identificar diversas iniciativas que, aunque con alcances limitados y de orden local, reafirman la preocupación por proveer de mejores condiciones de habitabilidad a las ciudades existentes en relación con las alternativas de la movilidad. Los recientes megaproyectos del High Line en Nueva

48 Porto y Pozueta, 2008. 
FIGURA 11. ESPACIO COMPARTIDO EN HEIDELBERG, ALEMANIA.

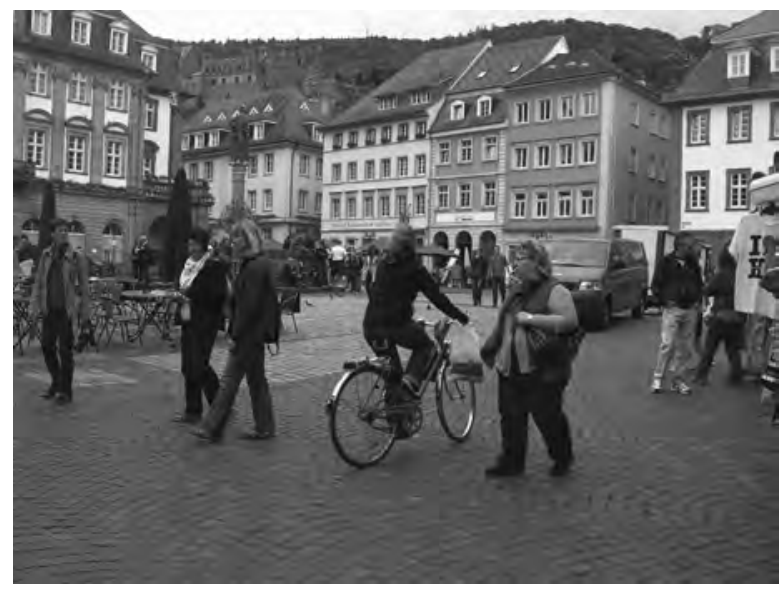

Fuente: autor

FIGURA 12. DIAGRAMA DEL T.O.D. DE CALTHORPE.

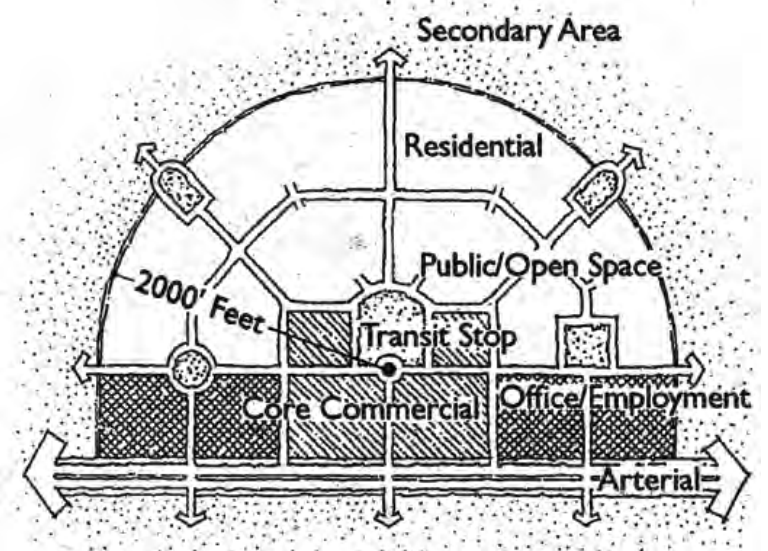

Fuente: placemakers.com 
York y el Central Artery/Tunnel Project (CA/T), conocido como el Big Dig en Boston, corroboran la necesidad de asumir los desafíos de la movilidad desde cualquier escala, reemplazando infraestructuras ferroviarias y de tráfico rodado por parques y espacios públicos varios. En tal sentido y en cuanto a concebir la movilidad como parte fundamental en la concepción de la estructura urbana y en especial como instrumento a la hora de plantear nuevas ciudades y distritos, resulta imprescindible recordar los aportes de Peter Calthorpe en cuanto al TransitOriented Development (T.O.D. ${ }^{49}$, cuya característica principal es el diseño sistémico de la movilidad. Calthorpe es uno de los miembros fundadores del Nuevo Urbanismo -como se mencionó anteriormente-, y por tanto asimilable a las vertientes neotradicionales; no obstante ha ejercido una influencia transversal en el diseño urbano contemporáneo, optando por modelos más compactos que no dependan entera y exclusivamente del automóvil. Sus propuestas se ordenan en torno a estaciones de transporte público, las cuales se sitúan en consideración al tiempo de desplazamiento del peatón, el que no debiera superar los 10 minutos de caminata, equivalente a los 2000 pies de radio que indica su diagrama. Los T.O.D. como también los Pedestrian Pockets que propone Calthorpe, son concepciones que regulan el crecimiento y desarrollo de los asentamientos humanos desde una visión multiescalar y multisistémica, en donde la movilidad juega un rol fundamental en la estructuración de los barrios y la inserción de ellos a nivel regional; una movilidad dirigida hacia el transporte público, la bicicleta y el peatón, marcando las distintas escalas que definen a la vez la forma recomendable para desplazarse. Paralelamente, el T.O.D. contempla densidades residenciales moderadas y altas, complementadas por diversos usos públicos, de trabajo, comercio minorista y servicios aglutinados en promociones de usos mixtos, y ubicados estratégicamente a lo largo de la red regional de transporte. Según el propio Calthorpe, el T.O.D. es un concepto que se puede reconocer en otros planteamientos recientes como los mismos Pedestrian Pockets, los Tradicional Neighborhoods Developments, los urban villages europeos y las Compact Communities, por nombrar algunos; aunque diversos en cuanto a detalle y a énfasis, comparten similares perspectivas, en cuanto a los principios de diseño y conjunto de objetivos que denotan una convergencia manifiesta. El T.O.D. es sin duda un instrumento que llama al consenso en cuanto a su racionalidad y aplicabilidad, permitiendo diversas interpretaciones y adecuaciones que trascienden las distintas aproximaciones y enfoques.

49 Calthorpe, 1993. 


\section{Aproximaciones ecológicas; un anhelo de sostenibilidad}

La fuerza de la evidencia respecto a la insostenibilidad del desarrollo predominante ha congregado progresivamente a idearios de distintos orígenes. La preocupación por el medio ambiente, los recursos no renovables, el calentamiento global, la huella de carbono, los acelerados procesos de urbanización en los países emergentes -especialmente en los países del $\mathrm{BRIC}^{50}$-, han desencadenado variadas reacciones en el ámbito de la arquitectura y del diseño urbano desde diversas escalas y aproximaciones, no tan solo desde la disciplina, sino que también desde la emergencia de una conciencia ciudadana. Se busca por un lado, la construcción de comunidades más sostenibles a partir de mecanismos y estrategias innovadoras, con nuevas tecnologías aplicadas en las edificaciones que reduzcan el impacto sobre el medio natural, mientras que por otro lado, se orientan los esfuerzos hacia la concepción de nuevas modalidades de ordenamiento territorial y de modelos urbanos más compactos que, junto a una visión integral de desarrollo económico y social, planteen alternativas reales y viables al modelo imperante.

50 BRIC se refiere a las potencias emergentes de Brasil, Rusia, India, China.
Existe una amplia gama de esfuerzos por articular este discurso ecologista en relación a la arquitectura en su concepción multiescalar, esfuerzos que se originan y se desarrollan desde diversos idearios, unos más cercanos a la protección del medio ambiente natural, y otras tendencias más afines con la innovación tecnológica en función de un desarrollo sostenible. Las líneas que velan por la protección del medio ambiente natural provienen en términos generales de idearios conservacionistas, de su versión más radical consolidada en las líneas preservacionistas y de las ramas de la ecología profunda; pueden ser caracterizadas como más dogmáticas, propugnando una transformación económica y social. Las otras tendencias señaladas en relación a la innovación tecnológica, se inclinan por orientar la dinámica del desarrollo actual hacia la exploración e implementación de tecnologías más sostenibles que ayuden a mitigar y eventualmente revertir los procesos de destrucción sistemática de los recursos y del medio ambiente, siendo esta vertiente la que alimenta fundamentalmente el desarrollo de proyectos e intervenciones urbanas con el "sello" de ecológico. Estas vertientes incorporan en sus principios los aspectos de sostenibilidad social y económica, los cuales conforman parte fundamental de las nuevas propuestas que indagan en las necesidades comunitarias en pos de generar asentamientos que favorezcan a la convivencia y a la salud de sus moradores. 
FIGURA 13. EL CONCEPTO DE SYMBIOCITY EN HAMMARBY-SJÖSTAD.

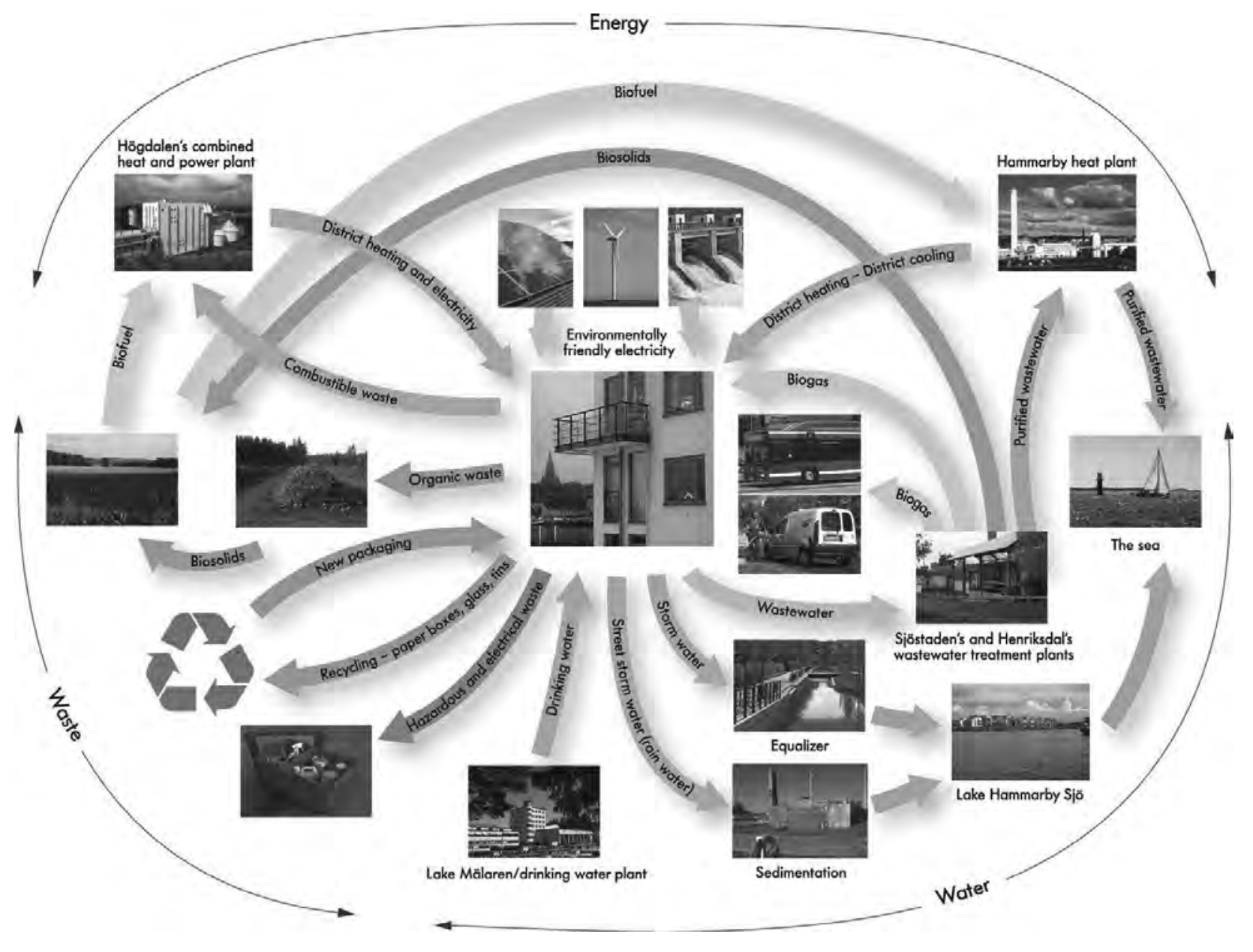

Fuente: http://www.hammarbysjostad.se/

152 revista invi № 79 / Noviembre 2013 / Volumen № 28: 125-163

ARTÍCULO: Tensiones y convergencia: El diseño urbano contemporáneo como alternativa a la ciudad dispersa y difusa / Constantino Mawromatis 


\section{FIGURA 14. MASTERPLAN DE HAMMARBY-SJÖSTAD.}

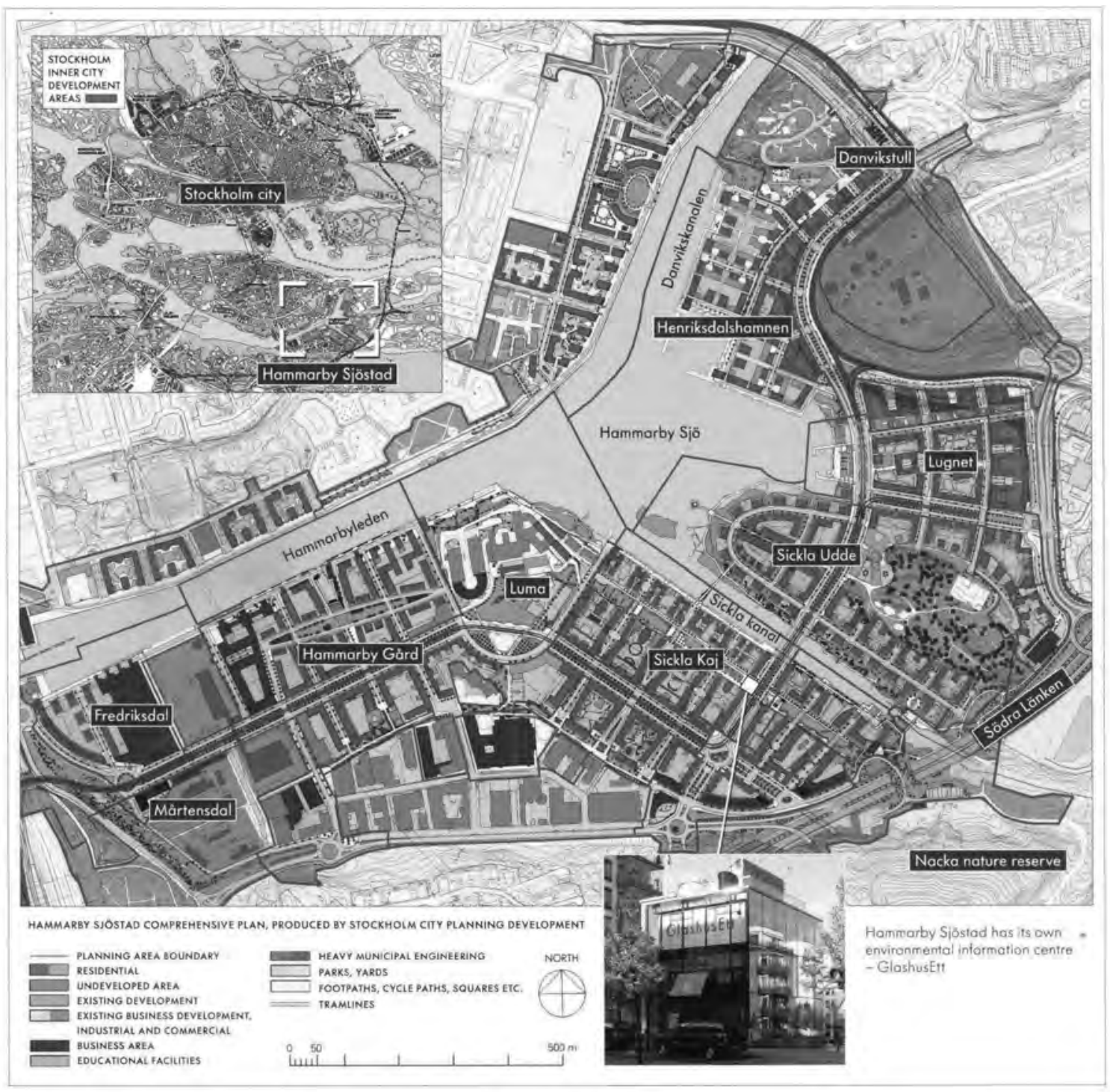

Fuente: Stockholm City Planning Development.

ARTíCULO: Tensiones y convergencia: el diseño urbano contemporáneo como alternativa a la ciudad dispersa y difusa / Constantino Mawromatis revista invi № 79 / Noviembre 2013 / Volumen N² 28: 125-163 153 
Resulta especialmente interesante la experiencia escandinava por su magnitud, relevancia, coherencia y por el carácter integral de sus diseños, instalándose como alternativa real al modelo hoy predominante, abordando desde aspectos morfológicos que favorecen las configuraciones compactas, la organización planimétrica y espacial que considera la escala humana y la conformación de comunidades, hasta aquellos aspectos multidisciplinares y tecnológicos que tienen relación con la movilidad, la energía, el manejo de residuos y la provisión de servicios básicos. Es el caso de los planteamientos de SymbioCity en Suecia, por su visión holística y por su proyección, con emprendimientos a gran escala como lo son el distrito de Hammarby-Sjöstad en Estocolmo y Västra Hamnen en Malmö, en un marco de asociatividad entre el sector público y el privado, y bajo una política que promueve la sostenibilidad urbana desde niveles locales a nacionales. SymbioCity es en concreto una marca registrada que refleja todos los conocimientos y experiencias del enfoque sueco de sostenibilidad.

Hammarby-Sjöstad es un distrito modelo, concebido en la década de los noventa en una antigua zona industrial, de muelles, dársenas y predios naturales que para el año 2018 se espera tendrá una población proyectada de 25.000 habitantes y 10.000 puestos de trabajo, aumentando considerablemente las densidades de las áreas periféricas de Estocolmo ${ }^{51}$. Es un proyecto holístico en el sentido que integra aspectos de habitabilidad, de morfología urbana, de movilidad, de acondicionamiento físico ambiental, todo bajo un sistema integrado considerando la sostenibilidad del proyecto, emplazándose de manera considerada respecto al borde costero y a los humedales aún existentes en una simbiosis entre lo construido y lo natural. El proyecto recurre además, a la diversidad de escalas presentes en una ciudad, otorgando espacios públicos y semipúblicos que incentivan las distintas actividades cotidianas, con una especial sensibilidad frente a la escala humana y la presencia de áreas verdes con el correspondiente mobiliario urbano.

En la misma línea de los SymbioCities cabe destacar el proyecto de BO01 Västra Hamnen, una experiencia reciente en terrenos del antiguo astillero de la ciudad de Malmö, emplazada a orillas del estrecho de Öresund. En comparación al caso de Hammarby, Västra Hamnen se caracteriza por un avance en el diseño y en la implementación de tecnologías ambientalmente sostenibles, destacando además por su diversidad en la oferta arquitectónica y por el

51 La densidad de Hammarby Sjöstad registrada en el año 2005 es de 133 habitantes por hectárea, algo menor que el de la ciudad de Estocolmo. Gaffney, 2007, pág.8. 
FIGURA 15 Y 16. HAMMARBY-SJÖSTAD.

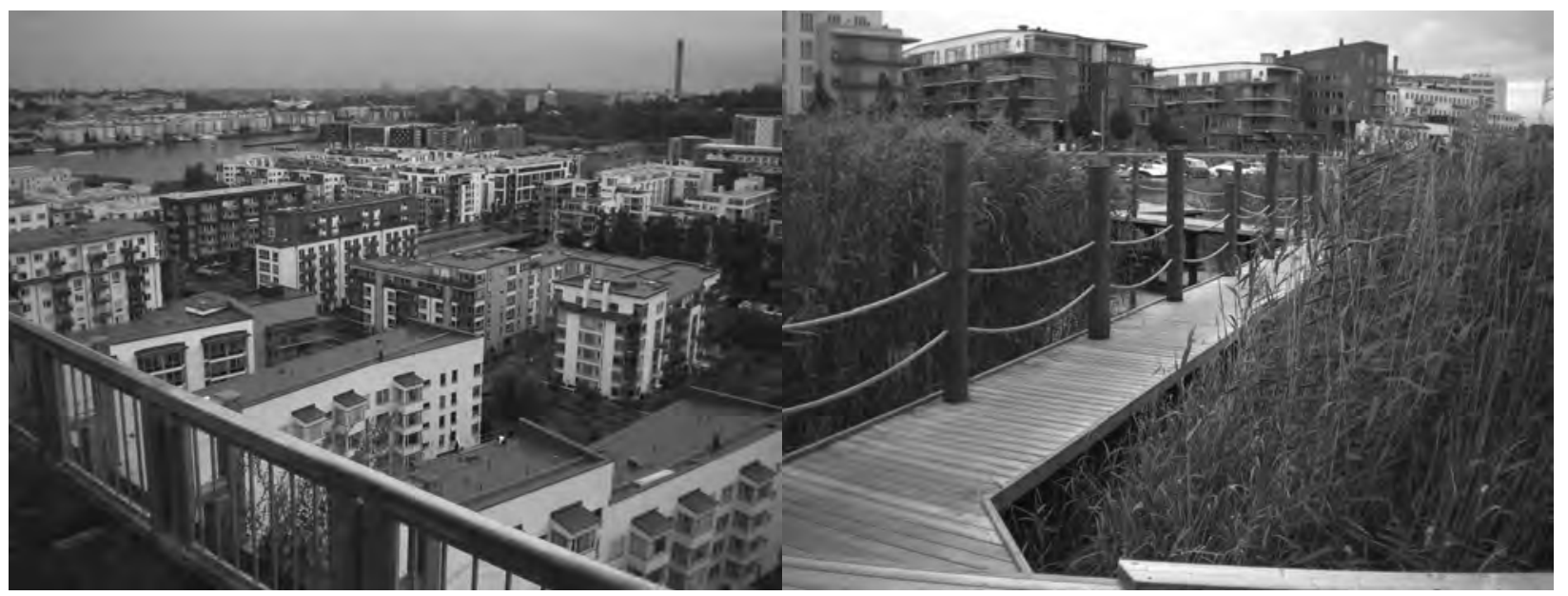

Fuente: autor.

depurado diseño de los espacios públicos, a una escala menor que busca singularizar las particularidades e identidades locales dentro del conjunto. Para ello se recurre -al igual que en las neo-aldeas urbanas-, a la conformación de micro-manzanas de aproximadamente 40 a 50 metros de longitud dispuestas con leves giros respecto a la trama ortogonal, generando de esta forma espacios públicos y semipúblicos de geometrías triangulares. El menor tamaño del grano urbano y la diversidad de los emprendimientos plantean además un compromiso con la democratización del desarrollo inmobiliario.
El modelo que presenta Hammarby-Sjöstad y Västra Hamnen es tecnológicamente innovador y de un pragmatismo propio de la cultura sueca. Con todo, su condición nítidamente contemporánea recoge no obstante en sus preceptos, muchos de los principios esenciales que han caracterizado las buenas prácticas en el diseño urbano más allá del contexto físico y cultural, con una preocupación especial hacia la escala humana, ofreciendo espacios públicos de calidad y con la diversidad programática necesaria para la animación de estos. Esta actitud trasciende el ámbito de los SymbioCities y refleja más bien la voluntad de capturar la esencia de los 
FIGURAS 17, 18 Y 19. VÄSTRA HAMNEN.

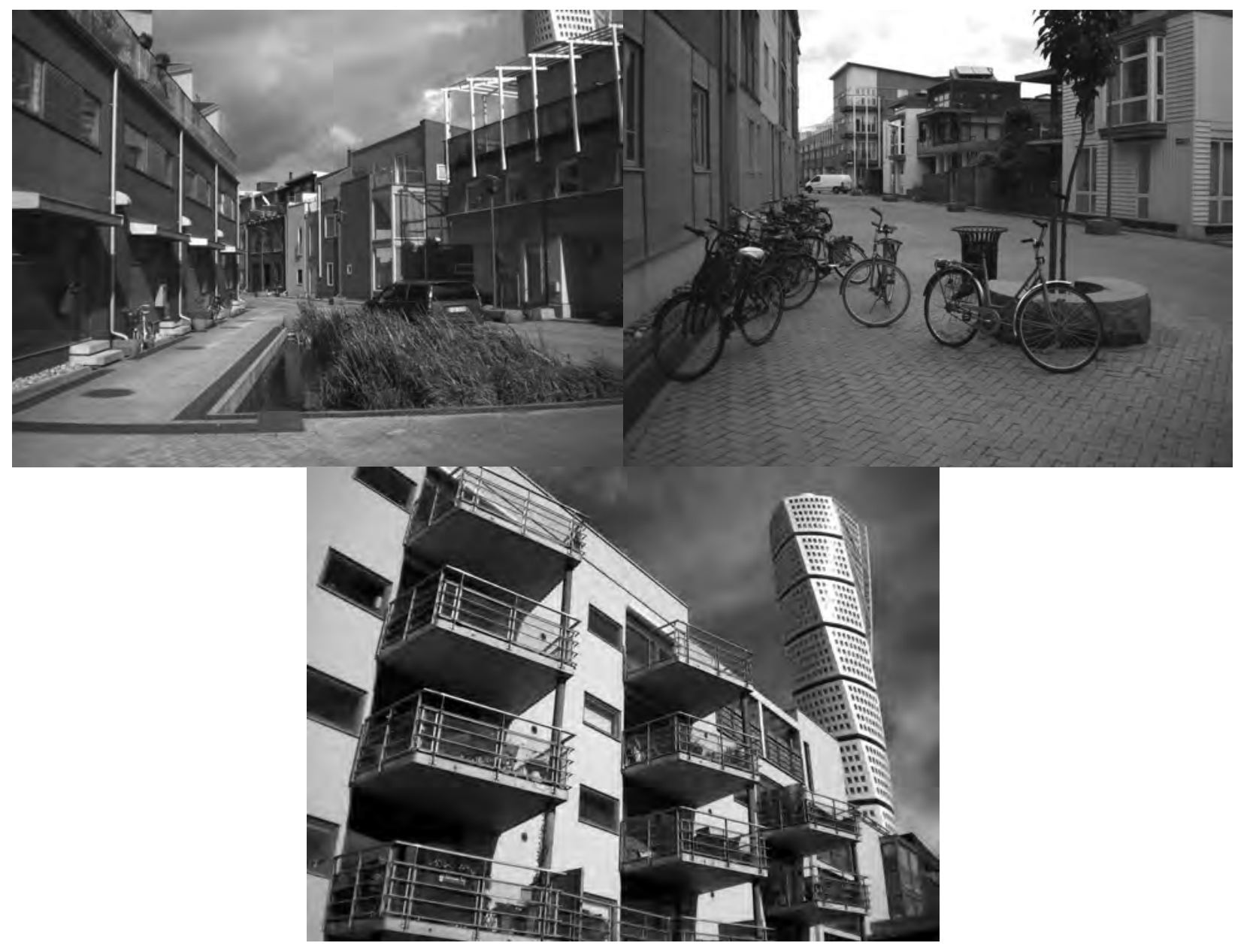

Fuente: autor. 
anhelos de la gente, velando por la sostenibilidad económica, social y medioambiental, y relevando con ello a la disciplina del diseño urbano.

Paralelamente a la experiencia sueca, se pueden identificar múltiples referentes que marcan una voluntad política hacia modelos más sostenibles, principalmente en los países del norte de Europa que lideran también las iniciativas en dirección a disminuir significativamente las emisiones de $\mathrm{CO}^{2}$, con medidas e incentivos directamente orientados al desarrollo urbano con un enfoque ecológico. En Alemania se releva el caso de la HafenCity, antiguamente la zona de descarga y almacenaje del puerto de Hamburgo, la cual siendo una intervención de regeneración urbana en áreas en desuso y deterioro, constituye una alternativa efectiva a la expansión hacia las periferias, adoptando una concepción sensible respecto al medioambiente con medidas concretas para una baja de las emisiones contaminantes, integrando aspectos morfológicos y de movilidad sostenible, e incluyendo una oferta variada de usos y edificios que vitalizan los generosos espacios públicos que ofrece el proyecto. HafenCity contempla de hecho, la renovación de 158 hectáreas en el área urbana sin necesidad de expandirse a la periferia, lo cual junto a la política de la ciudad de Hamburgo en cuanto reducir las emisiones contaminantes en 40\% para el año 2020 respecto a 1990, la sitúan entre los proyectos líderes de las corrientes ecológicas en el diseño urbano contemporáneo.
Otro ejemplo alemán lo constituye el distrito de Vauban en Friburgo -mencionado anteriormente a propósito de su postura innovadora frente a la movilidad-, que junto a la experiencia de Tübingen entre otras, nace y se desarrolla a partir de la participación ciudadana organizada en torno a una agenda ecológica. Es conocida como la ciudad verde de Alemania, construida bajo estándares de ahorro energético que integra la generación de energía solar entre otras medidas que la han posicionado como referente del urbanismo y la arquitectura sostenible. Estos proyectos se caracterizan por su arquitectura innovadora, no obstante recurren a formulas tradicionales en cuanto a la provisión de espacios a escala humana, a la diversificación de la oferta residencial y a la mezcla de usos.

En España por otro lado, se reconocen iniciativas locales que buscan mejorar las condiciones de sostenibilidad de las ciudades existentes, destacando la experiencia de la planificación integrada de los ensanches de Vitoria, ciudad nominada como la capital verde europea 2012. Semejantemente, y a partir de la voluntad de innovar en la planificación de nuevas ciudades o distritos desde una concepción sostenible, se destacan los referentes de las ecociudades de Sarriguren, Valdespartera y el proyecto de Logroño del estudio de MVRDV, entre otros casos que se abordan a partir de un ideario "eco-tecnológico", y que sin embargo en algunos casos constituyen aún modelos de baja conectividad respecto a su entorno urbano, 


\section{FIGURA 20. HAFENCITY.}

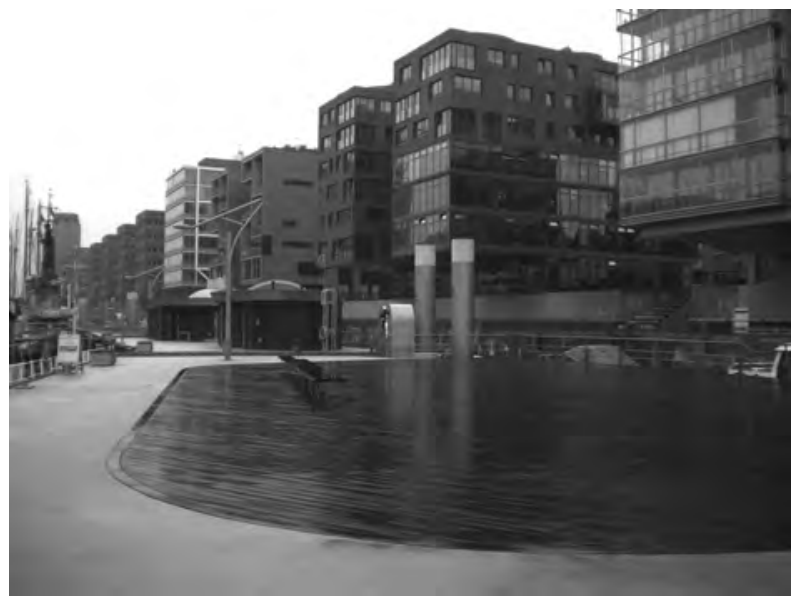

Fuente: autor

\section{FIGURA 21. VAUBAN.}

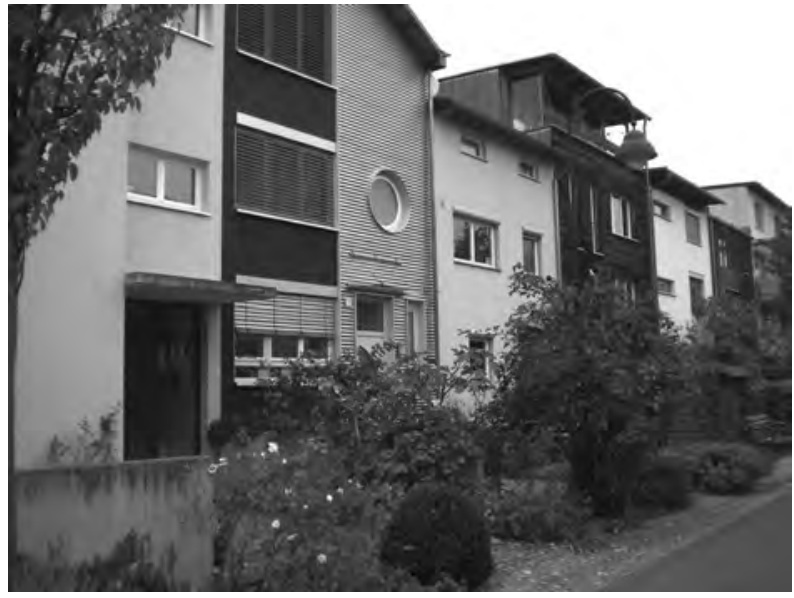

Fuente: autor 
siendo mayormente dependientes del automóvil. Las llamadas "ecociudades" españolas son proyectos configurados por un grano urbano de mayor escala y por edificios tipo bloque con menor grado de diversidad, pudiendo situárselas en la senda evolutiva del urbanismo racionalista, a diferencia de las SymbioCities suecas o el caso de Vauban que representan un modelo que se sustenta en la escala humana y en las estructuras comunitarias propias de su tradición, insinuando un posible campo de convergencia entre estas corrientes y los idearios neotradicionales.

En el contexto norteamericano por otro lado, a mediados de la década de los noventa se hace evidente un amplio consenso respecto a los problemas que acarrea la expansión urbana descontrolada y su impacto medioambiental. A finales de los ochenta se empieza a utilizar el concepto de crecimiento inteligente que surge como tal desde la esfera de la microeconomía ${ }^{52}$. Esta idea se comienza a articular en torno a los temas urbanos y concretamente como reacción a la expansión urbana descontrolada, conformándose en 1996 una red a escala nacional en los Estados Unidos, el Smart Growth Network, que convoca a 32 entidades de los sectores público y privado junto a organizaciones no-gubernamentales interesadas en la aplicación de los principios del crecimiento inteligente ${ }^{53}$.

52 Gavinha y Sui, 2003, referenciando a Poza, 1989.

53 Gavinha y Sui, 2003.
Claramente esta visión del desarrollo urbano sostenible transita en la misma dirección de las corrientes que provienen de orígenes y aproximaciones distintas, como es el caso del movimiento neotradicional del Nuevo Urbanismo, lo cual se puede constatar en la declaración de sus principios. El crecimiento inteligente es en efecto una instancia de encuentro de una diversidad de actores e intereses que confluyen en la construcción de la ciudad buscando nuevas formas de crecimiento, impulsando la economía, protegiendo el medio ambiente y la salud pública, y mejorando la vitalidad de las comunidades. Es quizás la evidencia más palpable de una real alternativa a la preponderancia de la ciudad dispersa y difusa, que en el tiempo puede de hecho generar un cambio cualitativo en el desarrollo urbano contemporáneo.

\section{Conclusiones}

Las diversas aproximaciones hacia el diseño urbano alternativo se pueden situar históricamente como parte de la evolución del discurso crítico frente a las transformaciones urbanas de la posguerra, que en sus comienzos se orienta a las consecuencias físicas y sociales del urbanismo racionalista-funcionalista para luego centrarse en los impactos del modelo norteamericano de la ciudad dispersa y su 
FIGURA 22. SARRIGUREN, PAMPLONA.

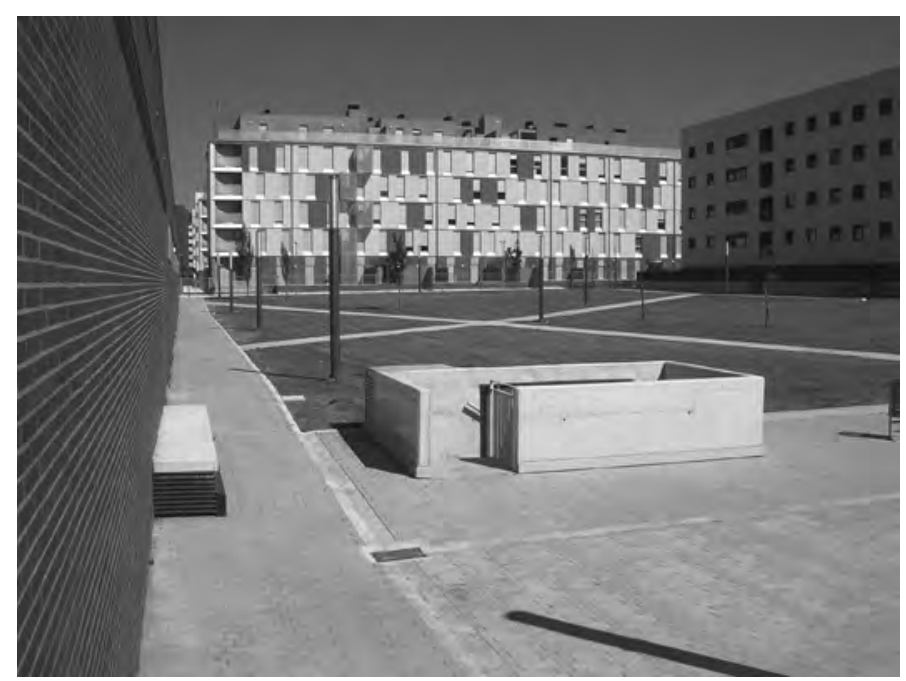

Fuente: autor

vínculo con la industria automotriz. La crítica por tanto, puede entenderse a partir de una problemática común que convoca a las distintas corrientes de pensamiento -en este caso definidas en relación a los tres enfoques-, pero que sin embargo reaccionan desde sus particulares sensibilidades y visiones. Vale decir, desde una aproximación arquitectónica, recurriendo a la tipología edificatoria y a la tradición de la disciplina del diseño urbano con los movimientos neotradicionales; desde la movilidad y la preocupación por la creciente dependencia del automóvil y por la pérdida de las condiciones apropiadas para la utilización del espacio urbano; y desde la inquietud por la creciente insostenibilidad ambiental del modelo de desarrollo vigente, el consecuente deterioro de las condiciones de habitabilidad y el agotamiento de los recursos naturales.

Estos tres enfoques de aproximación al diseño urbano alternativo, aunque distintos en sus orígenes, apuntan ciertamente hacia un logro común que busca crear mejores ciudades para sus habitantes conformando una real alternativa al crecimiento disperso y difuso. La magnitud y los alcances de las corrientes que propugnan dicho desarrollo 
alternativo, sugieren la existencia relativamente reciente de un fenómeno de fortalecimiento del diseño urbano como disciplina, lo cual se puede apreciar tanto en el contexto europeo y norteamericano, como crecientemente a nivel global. La insostenibilidad del modelo disperso y difuso vigente, junto con los mayores niveles de participación ciudadana, tienen eco en las propuestas alternativas, las cuales convergen progresivamente hacia planteamientos inclusivos que capturan la esencia de la vida a escala humana y las necesidades de considerar sensiblemente el medio ambiente en sus modelos urbanísticos. El smart growth, proveniente de las tendencias neotradicionales en los Estados Unidos, es un ejemplo que integra las variables de la morfología y de la imagen urbana con un discurso de valoración de la movilidad sostenible y de la ecología, similar a la evolución que ha experimentado el Nuevo Urbanismo, el cual desde su manifiesto pragmatismo ha hecho suyo el discurso de la sostenibilidad.

Es claro el rumbo evolutivo que han tomado en líneas generales estas corrientes, adscribiendo crecientemente a conceptos y principios de sostenibilidad a partir de un común denominador ético y un sentido de realismo que permite la construcción de un referente alternativo real que convoca progresivamente a diversos actores que definen el rumbo de la ciudad contemporánea hacia una concepción holística del diseño urbano.

\section{Bibliografía}

AGENCIA Europea de Medio Ambiente. La expansión urbana descontrolada en Europa. [En línea]. EEA Briefing. (4), 2006. ISSN 1830-2254. [Fecha de consulta: 4 de octubre de 2012]. Disponible en: http://www.eea.europa.eu/es/publications/ briefing_2006_4

CALTHORPE, Peter. The next American metropolis. Ecology, community, and the American dream. Nueva York, EE.UU. 1993. 175 p. ISBN 1-878271-68-7.

COMISIÓN Europea Medio Ambiente. Ciudades que marcan nuevas cotas en ecoinnovación. [En línea]. Comisión Europea. 2011. [Fecha de consulta: 6 de septiembre de 2012]. Disponible en: http://ec.europa.eu/environment/ ecoap/about-eco-innovation/good-practices/ eu/707_es.htm

CONGRESS for the New Urbanism. Charter of the New Urbanism. New York, McGraw Hill. 1999. 194 p. ISBN 0-07-135553-7.

CRAWFORD, J.H. Carfree cities. Utrecht, International Books. 2000. 323 p. ISBN 9057270374

EASTERLING, Keller. American town plans. A comparative time line. New York, Princeton Architectural Press. 1993. 119 p. ISBN 1-878271-69-5.

EUROPEAN Environment Agency. Urban sprawl in Europe - The ignored challenge. [En línea]. EEA Report. (10), 2006. [Fecha de consulta: 6

revista invi № 79 / Noviembre 2013 / Volumen № 28: 125-163 161 
de octubre de 2012]. ISSN 1725-9177. Disponible en: http://www.eea.europa.eu/publications/ eea_report_2006_10

GAFFNEY, Andrea, HUANG, Vinita, MARAVILLA, Kristin y SOUBOTIN, Nadine. HAMMARBY SJÖSTAD Stockholm,Sweden: A Case Study. [En línea]. Andrea E Gaffney. 2007. [Fecha de consulta: 21 de marzo de 2013]. Disponible en: http://www.aeg7.com/ assets/publications/hammarby\%20sjostad.pdf

GAVINHA, José A. y SUI, Daniel Z. Crecimiento inteligente - Breve historia de un concepto de moda en Norteamérica. [En línea]. Scripta Nova. 7(146, 039), 2003. [Fecha de consulta: 29 de diciembre de 2011]. Disponible en: http:// www.ub.edu/geocrit/sn/sn-146(039).htm

GEHL, Jan. La humanización del espacio urbano, la vida social entre los edificios. Barcelona, Reverté. 2006. 217 p. ISBN 84-291-2109-9.

JAMES-CHAKRABORTY, Kathleen. Kirchsteigfeld a European perspective on the creation of community. [En línea]. Places. 14(1), 2001. [Fecha de consulta: 14 de octubre de 2012]. Disponible en: http://escholarship.org/uc/item/6904w658

KATZ, Peter. The new urbanism: toward an architecture of community. New York : McGraw-Hill. 1994. 245 p. ISBN 0-07-033889-2.

KOSTOF, Spiro. The city assembled, the elements of urban form through history. Boston, Little, Brown. 1992. 320 p. ISBN 0-8212-1930-8

KRIEGER, Alex [et al.]. Andres Duany and Elizabeth Plater-Zyberk: Towns and town-making principles. Cambridge, Mass., Harvard University Graduate School of Design; New York : Rizzoli. 1991. 120 p. ISBN 0-8478-1436-X.

LÓPEZ Pérez, John Fredy; DELGADO Gómez, Dora Luz y VELASCO Torres, Liliana. La interfase urbano rural como territorio y espacio para la sostenibilidad ambiental. [En línea] Revista Ingenierías Universidad de Medellín. 4 (7):29-41, julio 2005. [Fecha de consulta: 05 de octubre de 2012]. Disponible en: http://redalyc.uaemex.mx/src/inicio/ ArtPdfRed.jsp?iCve=75004703

MATTOS, Carlos A de. Santiago de Chile, globalización y expansión metropolitana: lo que existía sigue existiendo. EURE. 25(76): 29-56, diciembre 1999. [Fecha de consulta: 6 de octubre de 2012]. Disponible en: http://dx.doi.org/10.4067/ S0250-71611999007600002

MO0R, Malcolm, ed. y ROWLAND, Jon, ed. Urban design futures. London, Routledge. 2006. 216 p. ISBN 0-415-31878-5.

PORPHYRIOS, Demetri y PAPADAKIS, Andreas. Leon Krier: Houses, palaces, cities. An architectural design profile. Londres, Reino Unido, AD Editions. 1984. 128 p. ISBN 0-312-47990-5. Architectural Design.

PORTO SCHETTINO, Mateus y POZUETA ECHAVARRI, Julio. Los espacios compartidos ("Shared Space"). Madrid, Instituto Juan de Herrera. 2008. Cuadernos de Investigación Urbanística N59.

POZUETA ECHAVARRI, Julio, dir. La ciudad paseable. Recomendaciones para la consideración de los 
peatones en el planeamiento, el diseño urbano y la arquitectura. Madrid, España, CEDEX. 2009. 430 p. ISBN 978-84-7790-509-7

RICHARDSON, Harry W., ed. y BAE, Chang-Hee Christine, ed. Urban Sprawl in Western Europe and the United States. England, Ashgate. 2004. 325 p. ISBN 10: 0754637891. ISBN-13: 978-0754637899.

SALINGAROS, Nikos A. La ciudad compacta sustituye a la dispersión. En: INDOVINA, Francesco, ed. La ciudad de baja densidad: Lógicas, gestión y contención. Barcelona, Diputació de Barcelona. 2007.

SEVILLA BUITRAGO Álvaro, coord. Conflictos de la ciudad contemporánea: un sondeo internacional. [En línea]. Urban. (3): 107-137, marzo 2012. [Fecha de consulta: 5 de abril de 2013]. Disponible en: http://oa.upm.es/14549/1/Alvaro_Sevilla_Buitrago_Conflictos_de_la_ciudad_ contempor\%C3\%Alnea.pdf
SIEGEL, Charles. Le Plessis-Robinson: A Model for Smart Growth. [En línea]. Planetizen. 2012. [Fecha de consulta: 19 de marzo de 2013]. Disponible en: http://www.planetizen.com/node/57600

SIERRA Club. Population and Sprawl. Population Growth and Suburban Sprawl. A Complex Relationship. [En línea]. Sierra Club. s.f. [Fecha de consulta: 21 de septiembre de 2011]. Disponible en: http://www.sierraclub.org/sprawl/population/

\section{U.S. DEPARTMENT of Housing and Urban Develop-} ment. The State of the Cities, 2000: Megaforces Shaping the Future of the Nation's Cities. Fourth Annual Report. [En línea]. ERIC. 2000. [Fecha de consulta: 6 de octubre de 2012]. Disponible en: http://eric.ed.gov/?id=ED447232

WORLDWATCH Institute. Curbing sprawl to fight climate change. [En línea]. Worldwatch Institute. 2001. [Fecha de consulta: 4 de octubre de 2012]. Disponible en: http://www.worldwatch.org/ node/1701 